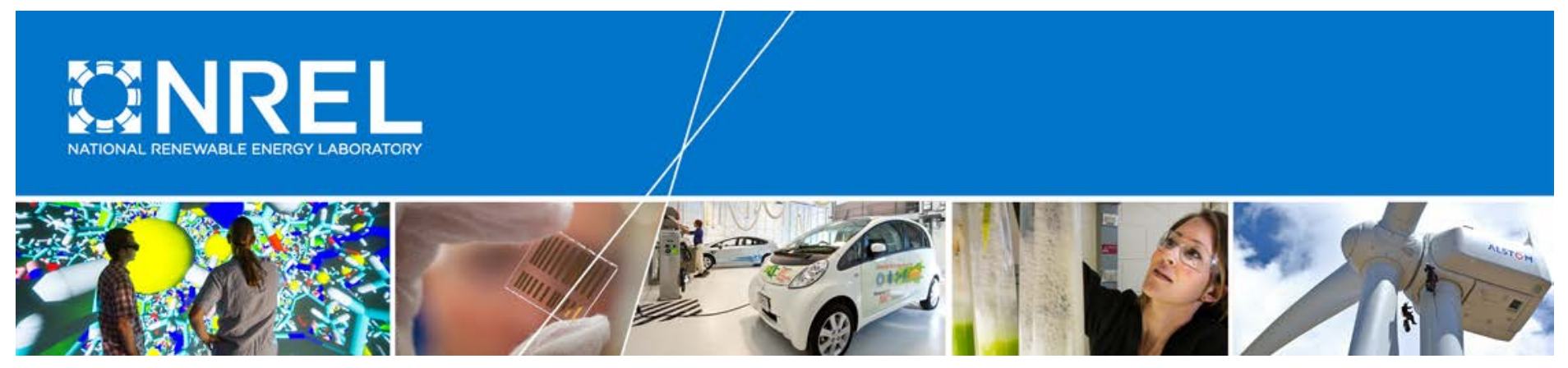

\title{
Wind Energy Industry Eagle Detection and Deterrents: Research Gaps and Solutions Workshop Summary Report
}

Karin Sinclair and Elise DeGeorge National Renewable Energy Laboratory

NREL is a national laboratory of the U.S. Department of Energy Office of Energy Efficiency \& Renewable Energy Operated by the Alliance for Sustainable Energy, LLC

This report is available at no cost from the National Renewable Energy Laboratory (NREL) at www.nrel.gov/publications.

Technical Report

NREL/TP-5000-65735

April 2016 


\section{Eagle Detection and Deterrents Research Gaps and Solutions Workshop Summary Report}

Karin Sinclair and Elise DeGeorge
National Renewable Energy Laboratory

Prepared under Task No. WE11.1005
National Renewable Energy Laboratory 15013 Denver West Parkway

Golden, CO 80401

303-275-3000 • www.nrel.gov
NREL is a national laboratory of the U.S. Department of Energy Office of Energy Efficiency \& Renewable Energy Operated by the Alliance for Sustainable Energy, LLC

This report is available at no cost from the National Renewable Energy Laboratory (NREL) at www.nrel.gov/publications.

\section{Technical Report}

NREL/TP-5000-65735

April 2016

Contract No. DE-AC36-08GO28308 


\title{
NOTICE
}

This report was prepared as an account of work sponsored by an agency of the United States government. Neither the United States government nor any agency thereof, nor any of their employees, makes any warranty, express or implied, or assumes any legal liability or responsibility for the accuracy, completeness, or usefulness of any information, apparatus, product, or process disclosed, or represents that its use would not infringe privately owned rights. Reference herein to any specific commercial product, process, or service by trade name, trademark, manufacturer, or otherwise does not necessarily constitute or imply its endorsement, recommendation, or favoring by the United States government or any agency thereof. The views and opinions of authors expressed herein do not necessarily state or reflect those of the United States government or any agency thereof.

The purpose of the workshop described in this report was to seek input from participants regarding technologies that detect and deter eagles from wind energy sites. Attendees were asked to provide input based on their personal experience, advice, information, or facts regarding this topic.

The objective of this workshop was not to obtain any group position or consensus. Rather, the U.S. Department of Energy was seeking as many recommendations as possible from all attendees. Participants were asked to refrain from passing judgment on each other's recommendations or advice and instead to concentrate on their own individual experiences.

This report is available at no cost from the National Renewable Energy Laboratory (NREL) at www.nrel.gov/publications.

Available electronically at SciTech Connect http:/www.osti.gov/scitech

Available for a processing fee to U.S. Department of Energy and its contractors, in paper, from:

\author{
U.S. Department of Energy \\ Office of Scientific and Technical Information \\ P.O. Box 62 \\ Oak Ridge, TN 37831-0062 \\ OSTI http://www.osti.gov \\ Phone: 865.576.8401 \\ Fax: 865.576.5728 \\ Email: reports@osti.gov
}

Available for sale to the public, in paper, from:

\author{
U.S. Department of Commerce \\ National Technical Information Service \\ 5301 Shawnee Road \\ Alexandra, VA 22312 \\ NTIS http://www.ntis.gov \\ Phone: 800.553 .6847 or 703.605 .6000 \\ Fax: 703.605.6900 \\ Email: orders@ntis.gov
}




\section{Acknowledgments}

The National Renewable Energy Laboratory would like to expressly thank the U.S. Department of Energy (DOE) Office of Energy Efficiency and Renewable Energy, Wind and Water Power Technologies Office, in particular Jocelyn Brown-Saracino, DOE, as well as Raphael Tisch and Samantha Eaves, Allegheny Science \& Technology (on behalf of DOE), for their support of this important workshop. We would also like to thank members of the steering committee who provided input on the objectives and content of the workshop including:

- Taber Allison, American Wind Wildlife Institute

- Heather Beeler, U.S. Fish and Wildlife Service

- Esteban Fernandez-Juricic, Purdue University

- Todd Katzner, U.S. Geological Survey

- Andy Stewart, University of Washington.

We would also like to thank Abby Arnold, with the American Wind Wildlife Institute, for her contributions to developing the workshop agenda and support of facilitation, and Susan Savitt Schwartz for her notetaking services. Finally, we would like to thank the workshop attendees, as listed in Appendix B, for their willingness to participate and contribute information and ideas throughout the workshop. 


\section{List of Acronyms}

$\mathrm{ACP}$

AWEA

AWWI

BGEPA

DOE

lidar

NREL

R\&D

SCADA

USFWS

USGS advanced conservation practices

American Wind Energy Association

American Wind Wildlife Institute

Bald and Golden Eagle Protection Act

U.S. Department of Energy

light detection and ranging

National Renewable Energy Laboratory

research and development

supervisory control and data acquisition

U.S. Fish and Wildlife Service

U.S. Geological Survey 


\section{Executive Summary}

The Bald and Golden Eagle Protection Act (BGEPA) ${ }^{1}$ prohibits the "take" of these birds. The act defines take as to "pursue, shoot, shoot at, poison, wound, kill, capture, trap, collect, destroy, molest or disturb." The 2009 Eagle Permit Rule (74 FR 46836) authorizes the U.S. Fish and Wildlife Service (USFWS) to issue nonpurposeful (i.e., incidental) take permits, and the USFWS 2013 Eagle Conservation Plan Guidance ${ }^{2}$ provides a voluntary framework for issuing programmatic take permits to wind facilities that incorporate scientifically supportable advanced conservation practices (ACPs). Under these rules, the Service can issue permits that authorize individual instances of take of bald and golden eagles when the take is associated with, but not the purpose of, an otherwise lawful activity, and cannot practicably be avoided.

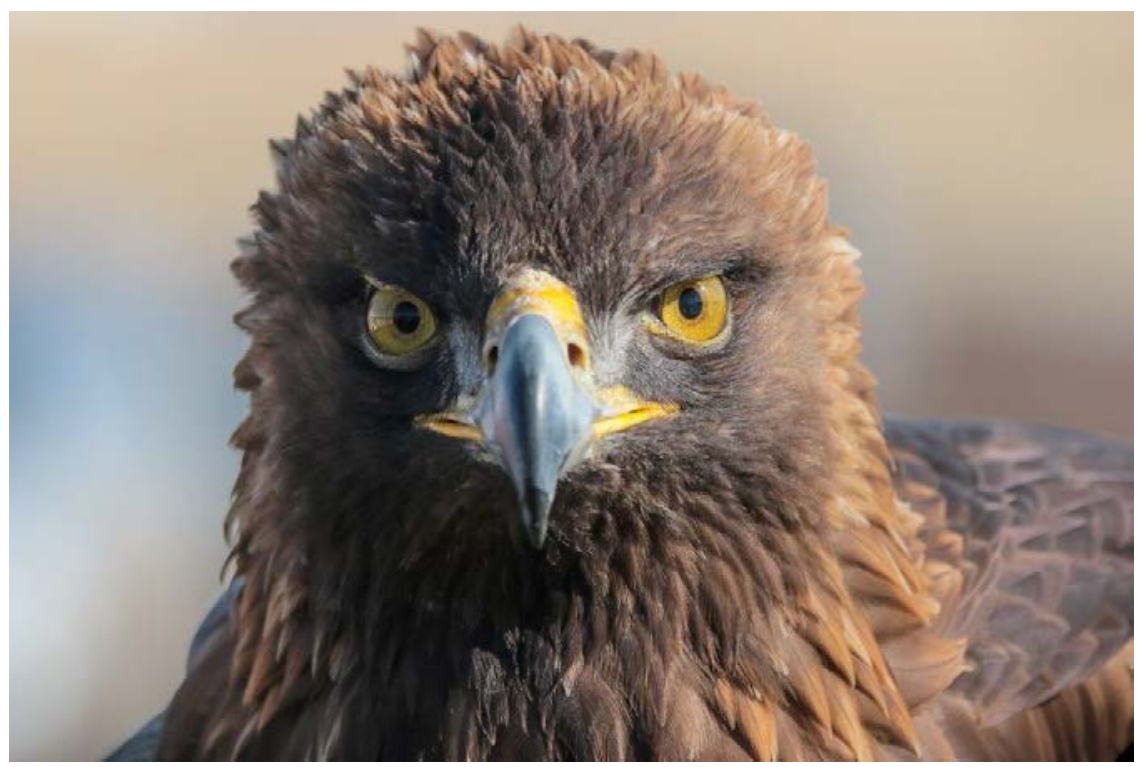

Figure ES1. Golden eagle. Photo by Lee Jay Fingersh, NREL 35724

To date, the USFWS has not approved any ACPs, citing the lack of evidence for "scientifically supportable measures." The Eagle Detection and Deterrents Research Gaps and Solutions Workshop was convened at the National Renewable Energy Laboratory in December 2015 with a goal to comprehensively assess the current state of technologies to detect and deter eagles from wind energy sites and the key gaps concerning reducing eagle fatalities and facilitating permitting under the BGEPA. During the workshop, presentations and discussions focused primarily on existing knowledge (and limitations) about the biology of eagles as well as technologies and emerging or novel ideas, including innovative applications of tools developed for use in other sectors, such as the U.S. Department of Defense and aviation.

The main activity of the workshop was the breakout sessions, which focused on the current state of detection and deterrent technologies and novel concepts/applications for detecting and minimizing eagle collisions with wind turbines. Following the breakout sessions, participants were asked about their individual impressions of the relative priority of each of the existing and novel ideas.

\footnotetext{
${ }^{1}$ See http://www.fws.gov/birds/management/managed-species/bald-and-golden-eagle-information.php.

${ }^{2} \mathrm{See}$ http://www.fws.gov/migratorybirds/pdf/management/eagleconservationplanguidance.pdf.
} 
Criteria considered included:

- Likelihood of success-i.e., probability that conducting research and development (R\&D) will yield useful, constructive results

- Ultimate affordability

- Ultimate efficacy

- Cost of R\&D and product commercialization

- Length of time to achieve commercial application.

The purpose of this exercise was to provide workshop participants with an opportunity to share their objective recommendations as influenced by their personal experiences, areas of expertise, and levels of knowledge on the topic. It was emphasized that this was an exercise, not a plan for R\&D.

Participants placed a very high level of emphasis on discussions of existing systems, including ideas that involve more independent field tests and validations of these systems. Improvements could include, but are not limited to, advancing the capability of visual cameras to detect eagles at wind power plants. There was also interest in gaining a better understanding about how eagles perceive and respond to visual and auditory stimuli (because their sensory systems are different from those of humans), which will be critical in developing novel, effective deterrent systems.

In addition, participants placed a high level of emphasis on utilizing integrated system components, including developing algorithms that will help viewers of optic data make operational decisions as well as gain a better understanding of when and under what conditions bird strikes occur.

Participants placed less emphasis on assessing secondary impacts, including habituation. Also given lower prioritization were studying deterrent placements, improving current auditory and visual deterrents, further developing solid-state Doppler radars and supervisory control and data acquisition interfaces, studying deterrent effects on humans, and improving passive acoustic monitoring. During the workshop, participants discussed that these focus areas were important activities, but, at the same time, they also indicated that initial research efforts should focus on addressing the gaps in our understanding of eagle sensory biology as well as refining core detection and deterrent systems. 


\section{Table of Contents}

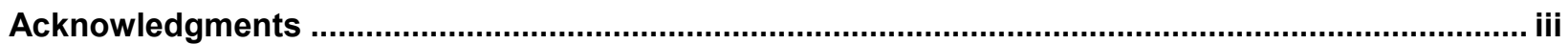

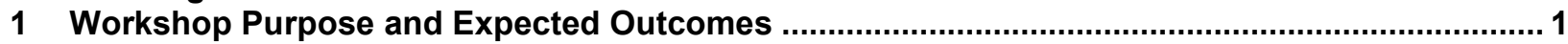

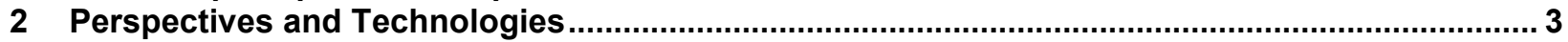

3 Detection and Deterrent Technology Developer Panel ................................................................ 7

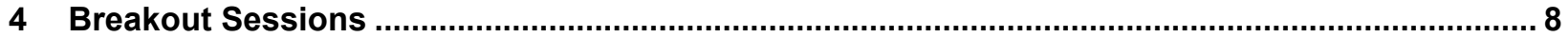

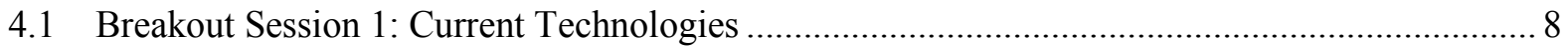

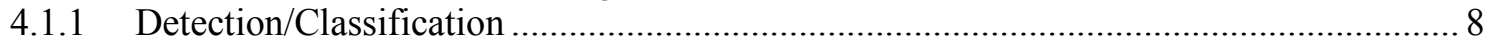

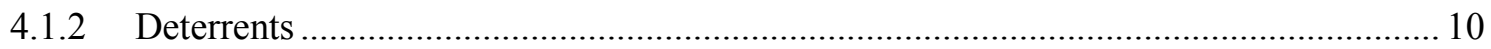

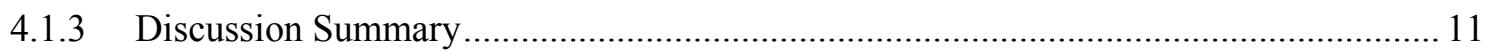

4.2 Breakout Session 2: Novel Concepts ......................................................................... 13

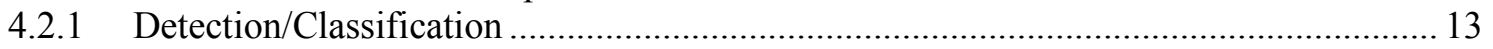

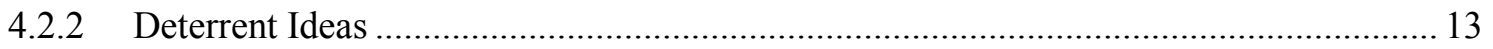

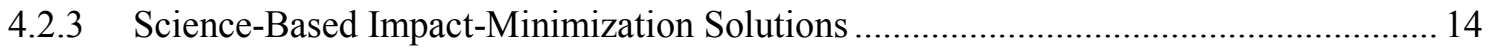

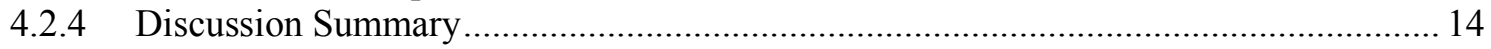

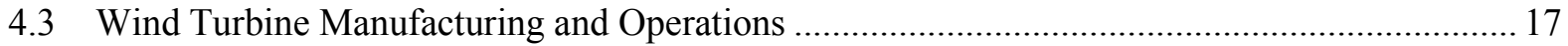

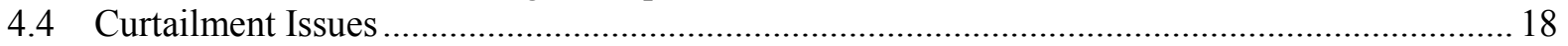

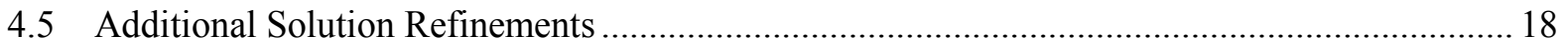

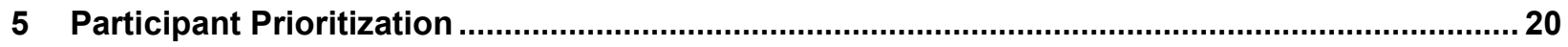

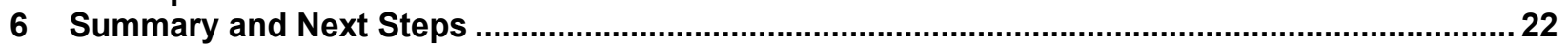

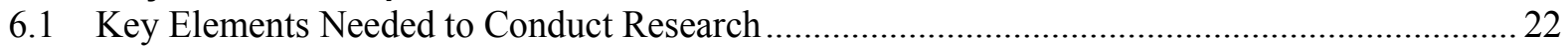

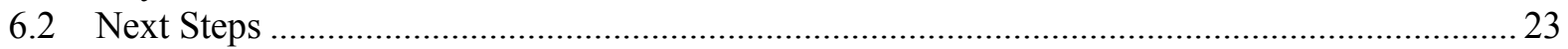

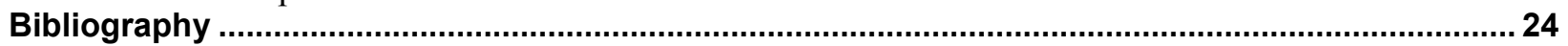

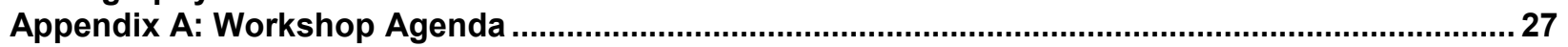

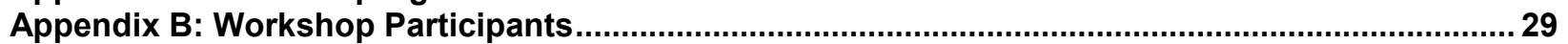

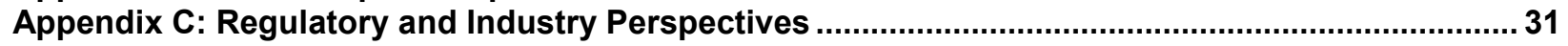

Eagle Act Regulations and the Regulatory Framework for Detect and Deter Technologies ............... 31

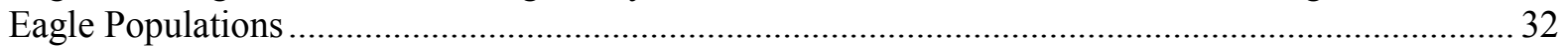

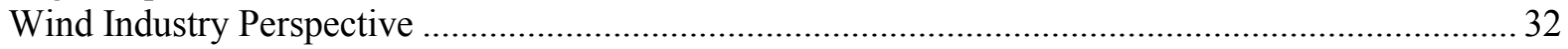

Appendix D: Biological and Physiological Perspectives........................................................... 34

Overview of Golden and Bald Eagle Habitat Association, Distribution, Biology, and Flight

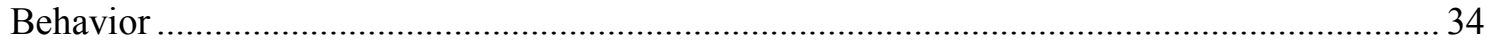

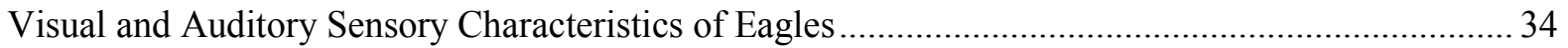

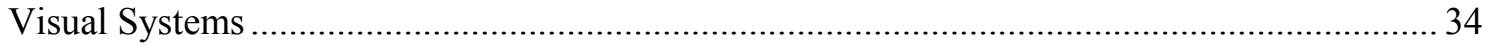

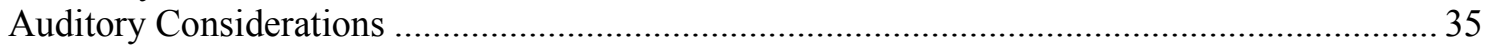

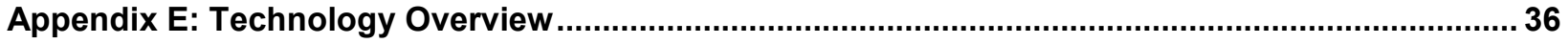

State of Eagle Detection and Deterrence Technology .................................................................. 36

Appendix F: Detection and Deterrent Technology Developer Panel Presentations ........................ 38 


\section{List of Figures}

Figure ES1. Golden eagle. Photo by Lee Jay Fingersh, NREL 35724 ......................................................

Figure 1. Golden eagle feeding. Photo from Chuck Waggy, AppalachianEagles.org ................................ 2

Figure 2. Bald eagle. Photo by Lee Jay Fingersh, NREL 35723 ...................................................... 3

Figure 3. A bald eagle helps test a radar and visual system at the National Wind Technology Center. Photo by Dennis Schroeder, NREL 35755 .......................................................................... 4

Figure 4. Golden eagle about to land. Photo by Dennis Schroeder, NREL 35749 ................................... 5

Figure 5. Testing detection systems for bald eagles at the National Wind Technology Center. Photo by

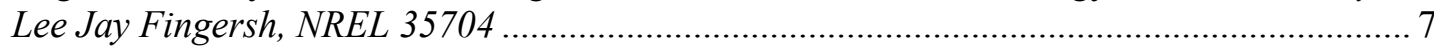

Figure 6. Bald eagle soaring with transmitter. Photo by Lee Jay Fingersh, NREL 35709 ........................ 9

Figure 7. Bald eagle with nictitating membrane. Photo by Lee Jay Fingersh, NREL ............................ 10

Figure 8. The impressive wing span of Spirit, a 20-year-old bald eagle. Photo by Lee Jay Fingersh, NREL 35731

\section{List of Tables}

Table 1. Summary of Technologies Identified During the Workshop..... 15 


\section{Workshop Purpose and Expected Outcomes}

The Eagle Detection and Deterrents Research Gaps and Solutions Workshop was convened at the National Renewable Energy Laboratory (NREL) in December 2015 to gain insights into key gaps and potential technology solutions that could yield "scientifically supportable measures" to reduce impacts on eagles at wind energy sites. These insights are intended to inform future research priorities, some of which could result in the adoption of advanced conservation practices (ACPs) by the U.S. Fish and Wildlife Service's (USFWS's) when issuing programmatic eagle take permits.

The Bald and Golden Eagle Protection Act (BGEPA) $)^{3}$ prohibits the "take" of these birds. The act defines take as to "pursue, shoot, shoot at, poison, wound, kill, capture, trap, collect, destroy, molest or disturb." The 2009 Eagle Permit Rule (74 FR 46836) authorizes the USFWS to issue nonpurposeful (i.e., incidental) take permits, and the USFWS 2013 Eagle Conservation Plan Guidance $^{4}$ provides a voluntary framework for issuing programmatic take permits to wind facilities that incorporate scientifically supportable ACP. But to date, the USFWS has not approved any advanced conservation practices, citing the lack of evidence for scientifically supportable measures.

Convening this workshop to assist in identifying potential detection and deterrent technologies was important because:

- Responsible siting and impact-mitigation tools are critical to realizing sustainable wind energy development.

- Reaching wind energy goals requires developing accepted technology solutions that provide the ability to detect and deter eagles and support the USFWS's issuance of BGEPA take permits.

\footnotetext{
${ }^{3}$ See http://www.fws.gov/birds/management/managed-species/bald-and-golden-eagle-information.php.

${ }^{4} \mathrm{See}$ http://www.fws.gov/migratorybirds/pdf/management/eagleconservationplanguidance.pdf.
} 


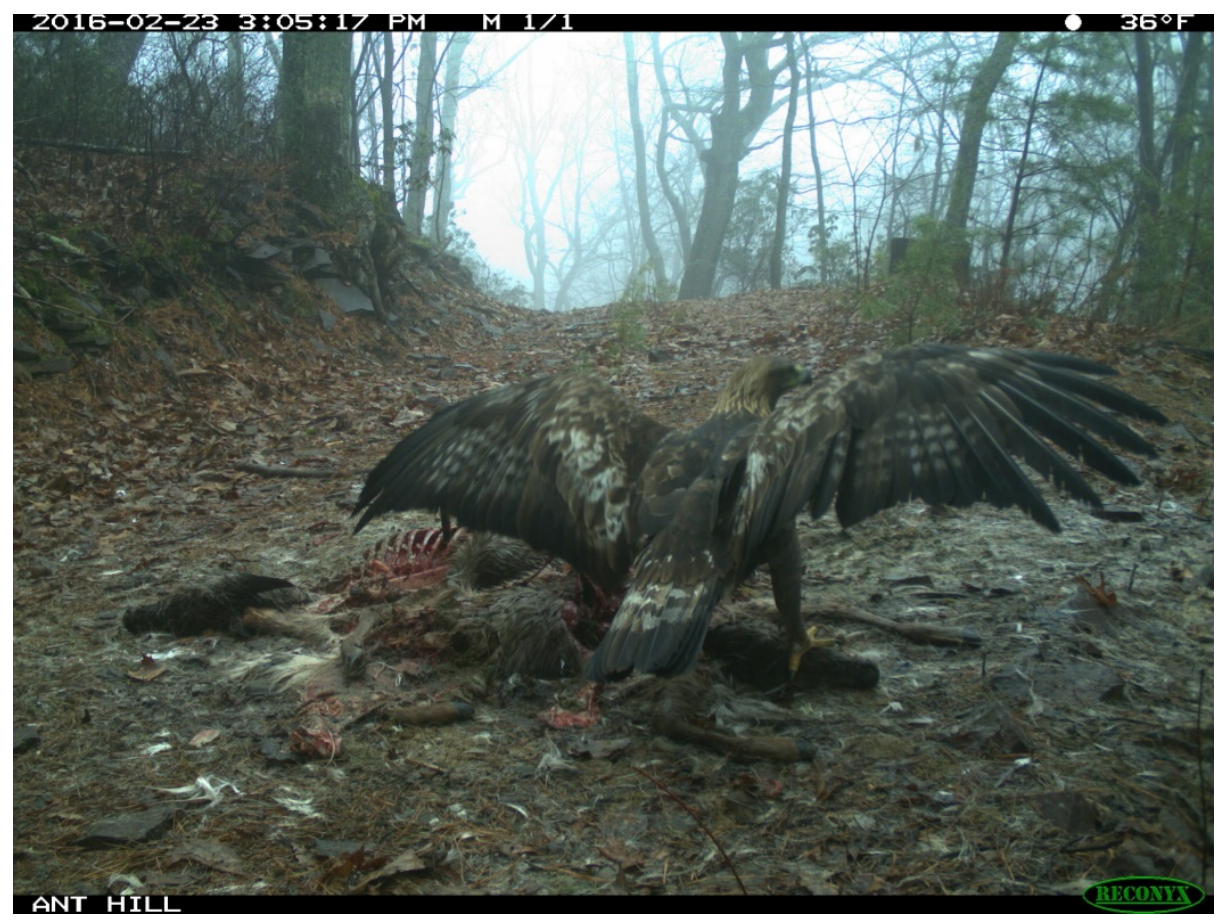

Figure 1. Golden eagle feeding. Photo from Chuck Waggy, AppalachianEagles.org

Workshop presentations and discussions did not focus on policy and regulatory considerations; instead, they focused on existing and emerging technologies. Novel ideas were also discussed, including applications of tools developed for use in other sectors, such as defense and aviation. Participants were asked to:

- Canvas a wide range of ideas, and bring their different perspectives to bear in identifying technology opportunities as well as constraints.

- Discuss near-term, middle-term, and long-term research and development (R\&D) needs.

- Connect with each other during the course of the workshop and seek opportunities to collaborate to bring promising ideas to fruition.

The workshop agenda (provided in Appendix A) was developed by a team from the U.S. Department of Energy and NREL with input from a steering committee (see Appendix B for a list of attendees and steering committee members). Additional support was provided by the American Wind Wildlife Institute (AWWI), which facilitated the workshop. The agenda was organized to provide perspectives from key sectors, brainstorm ideas in breakout sessions for existing and novel detection and deterrent technologies, develop tables to reflect the ideas expressed in the breakout sessions, and prioritize research areas. 


\section{Perspectives and Technologies}

Members of key sectors gave presentations to provide attendees with an understanding of the different perspectives represented in the workshop.

Kevin Kritz and Brian Millsap of the USFWS provided the regulatory perspective. Kritz provided some background on the BGEPA, 2009 Eagle Permit Rule, and 2013 document on Eagle Conservation Plan Guidance. He explained that, to date, no conservation measures have been scientifically demonstrated to reduce eagle disturbance and blade-strike mortality at wind projects; therefore, the USFWS has not approved any ACPs for these types of projects. The legal conundrum to this approach is that it is difficult to get a permit without proven ACPs, and proposed ACPs cannot be proven without scientific evaluation under operational conditions. The USFWS envisions working with industry to develop ACPs for wind projects as part of an adaptive management regime and comprehensive research program designed to obtain the scientific information needed to issue programmatic eagle take permits.

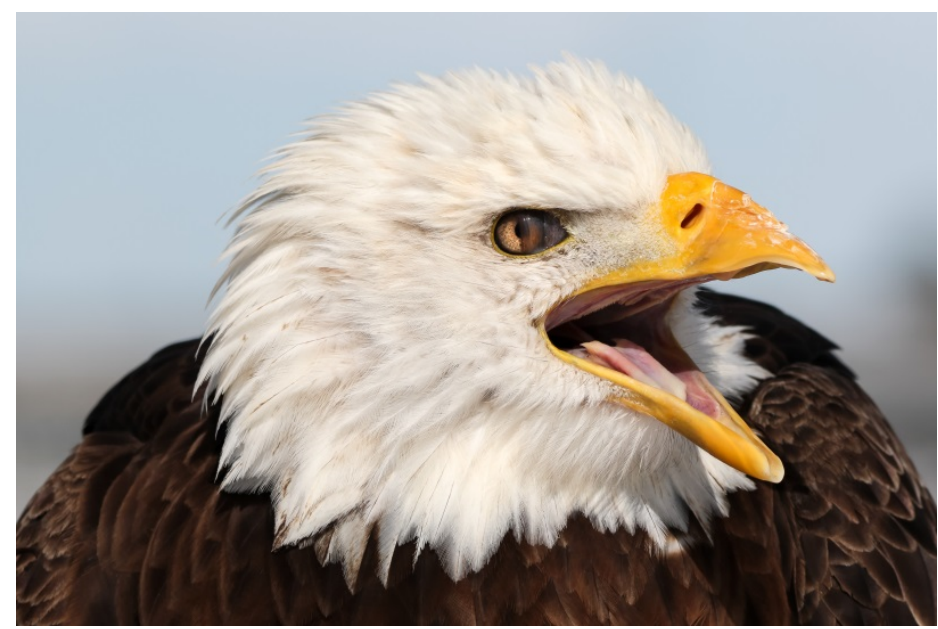

Figure 2. Bald eagle. Photo by Lee Jay Fingersh, NREL 35723

Millsap described the bald eagle population as healthy and resilient. According to the USFWS, at this time the take of a bald eagle, up to a point, is considered a legal issue, not a biological concern. A take rate for bald eagles that is greater than $8 \%$ (less in some places, such as the Southwest) would also be a population concern. For golden eagles, the situation is very different. Current populations can sustain a take rate of up to $10 \%$, but existing levels from all sources are already at or exceed $10 \%$, with overharvesting on the order of 1,000 golden eagles per year; therefore, it is critical to minimize fatalities of golden eagles from all anthropogenic activities. Programmatic take permits for wind energy sites must include mortality offsets from other sources if there is unavoidable take. Based on the best available data from the USFWS, starvation kills the most eagles (mostly juveniles), followed by poisoning and shooting. The USFWS suspects that a lot of the poisonings are from rodenticides, but not all are (some are from direct poisoned baiting), and many cannot be diagnosed to the exact compound. Illegal shooting and secondary poisoning from rodenticides are more difficult to mitigate than electrocutions, for which there are proven mitigation measures. 
John Anderson of the American Wind Energy Association (AWEA) provided the wind industry perspective. Anderson explained that the wind industry needs a suite of avoidance and minimization mechanisms that are effective at detecting and deterring eagles and are within known repair and replacement costs and manageable operational constraints. From the legal standpoint, greater certainty is needed about what is acceptable from the USFWS. Technologies need to be easily implementable and capable of being integrated into large-scale energy facilities without incurring untenable operational impacts. Anderson also stressed the importance of a coordinated, well-funded, comprehensive effort that involves technology developers, biologists, the wind industry, and regulators. It is crucial that this collective group states that wind energy is the single greatest, lowest cost, most easily deployable way to reduce carbon emissions, and that climate change is the single greatest threat not only to eagles but also to other wildlife.

Todd Katzner of the U.S. Geological Survey provided a biological perspective of golden and bald eagle habitat association, distribution, biology, and flight behavior. Katzner explained that eagles have a widespread distribution, with many similarities and some differences between the two species in terms of habitat, sensitivity to human disturbances and nesting cycles, diet, demography, and flight behavior. Regarding wind development's impact on eagles, Katzner suggests keeping in mind that eagles need food, updraft, and nesting sites. Eagle mortality at wind sites that intersect significantly with one or more of these factors can be high (e.g., Smøla, Norway; Altamont, California; and Wyoming).

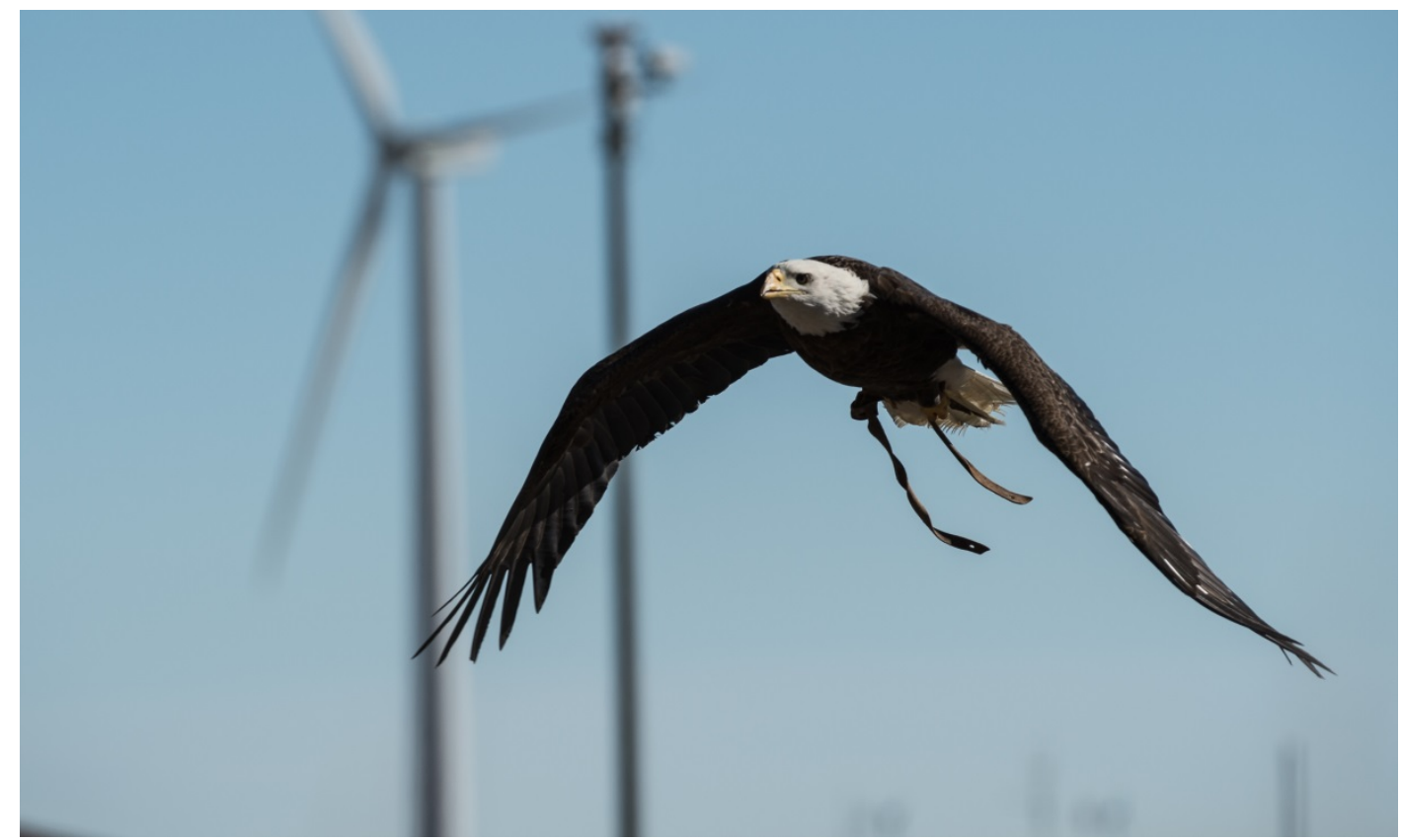

Figure 3. A bald eagle helps test a radar and visual system at the National Wind Technology Center. Photo by Dennis Schroeder, NREL 35755

Esteban Fernández-Juricic of Purdue University provided an account of what is known about how birds see their world. Fernández-Juricic explained that eagles rely heavily on vision, yet they collide with wind turbines, which are visually conspicuous to humans; however, given that there are differences in visual perception between humans and birds, wind turbines may not necessarily be conspicuous to eagles. In addition, it has been hypothesized that golden eagles 
tend to go into a "hunting trance," in which they utilize their remarkable visual acuity to look for slight movement below them while unaware of turbines spinning ahead of them. Unfortunately, there are a lot of gaps in our understanding about the golden eagle visual system. Addressing these gaps would allow researchers to develop deterrents around the golden eagle visual system to make turbines more visually conspicuous to these birds. The question is how to do this in a scientifically sound manner instead of via a trial-and-error approach to testing different stimuli. Fernández-Juricic suggests four steps: (1) characterize the visual system of the species of interest, (2) model the visual perception based on these characteristics, (3) develop novel stimuli, and (4) measure eagles' responses to stimuli.

Jeff Lucas of Purdue University presented on auditory considerations for eagles. Lucas explained that researchers can similarly characterize and measure the relevant properties of birds' (and specifically eagles') auditory systems to determine what auditory stimuli are most likely to deter them from entering a turbine risk zone or alert them to avoid colliding with turbines. However, very little is known at present about any aspect of eagles' auditory systems. Developing an effective auditory deterrent would require knowing more than the minimum sound level that eagles can hear. Researchers want to understand how eagles respond to louder sounds, different tones, amplitude modulations, and rapid frequency sweeps.

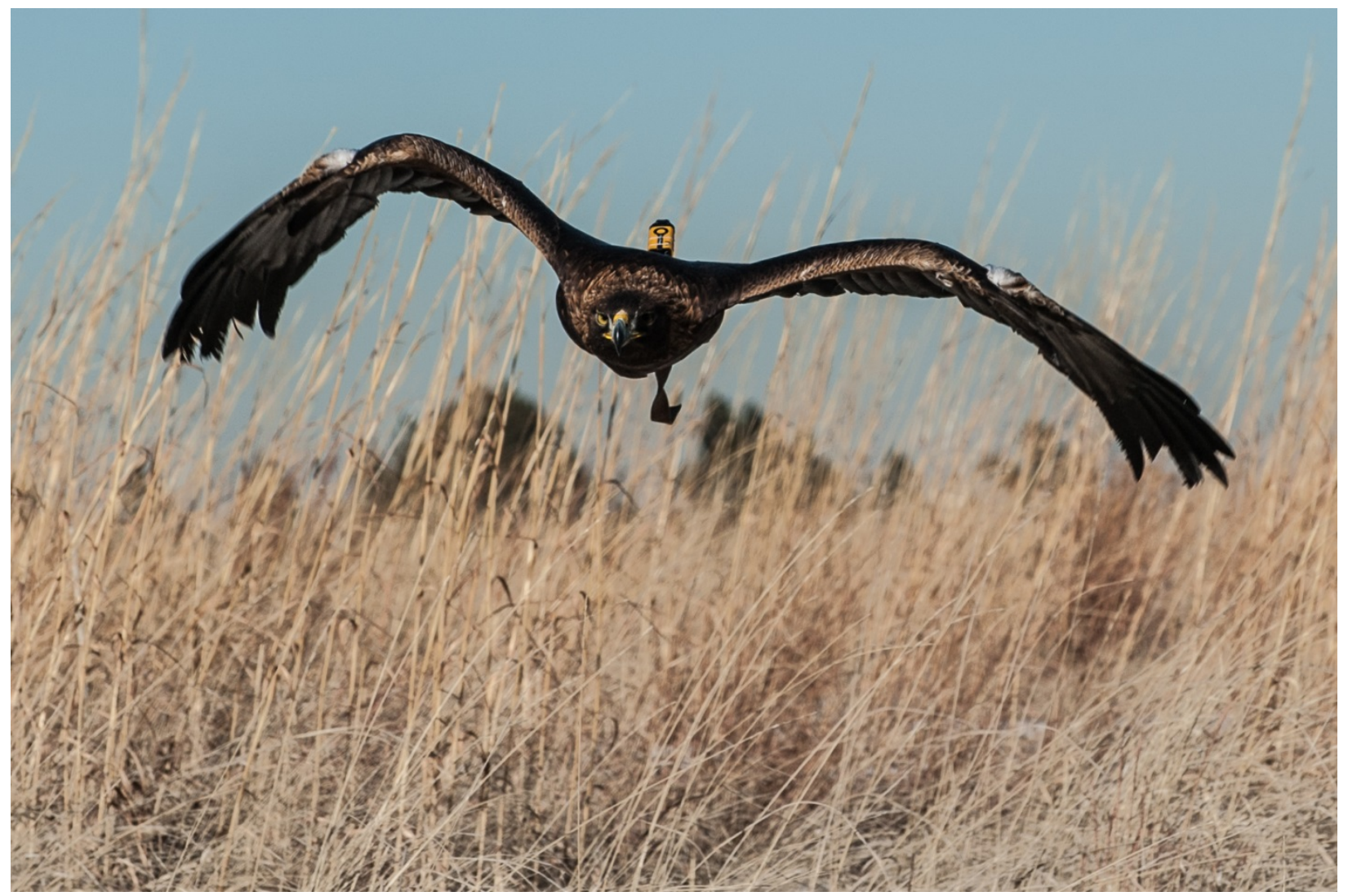

Figure 4. Golden eagle about to land. Photo by Dennis Schroeder, NREL 35749

Taber Allison of AWWI presented on the state of eagle detection and deterrent technologies at AWWI. Allison provided an update of AWWI's April 2014 technology workshop that focused on bats and raptors. Three primary outcomes from the workshop were that (1) there is no 
equipment impediment to feathering turbines below cut-in speed, a valuable finding that can be implemented quickly; (2) information on available technology needs to be shared; and (3) there is a need for independent evaluations. Key challenges to technology verification include:

- The absence of a definition of successful technology-i.e.,100\% reduction or some value below that

- The fact that eagle collisions with turbines are statistically rare events

- The need to ensure credibility of the technology verification approach

- The lack of sufficient funding to perform the verification testing.

For more information about the presentations given by the USFWS, the wind industry, and biologists as well as an overview of the status of detection and deterrent technologies, see the following appendices:

- Appendix C: Regulatory and Industry Perspectives

- Appendix D: Biological and Physiological Perspectives

- Appendix E: Technology Overview. 


\section{Detection and Deterrent Technology Developer Panel}

Workshop participants who are developing detection and deterrent systems were asked to participate in a technology developer panel to identify the research questions that will help improve detection and deterrent technology solutions. The presentations from this panel are provided in Appendix F.

During the workshop, discussions ensued on how to develop an acceptable understanding of testing that satisfies all parties. There was general agreement that integrating testing among multiple wind facilities would be beneficial. Including numerous facilities would help increase statistical power in the analyses; however, solutions will be needed to deal with issues of proprietary information to pool data.

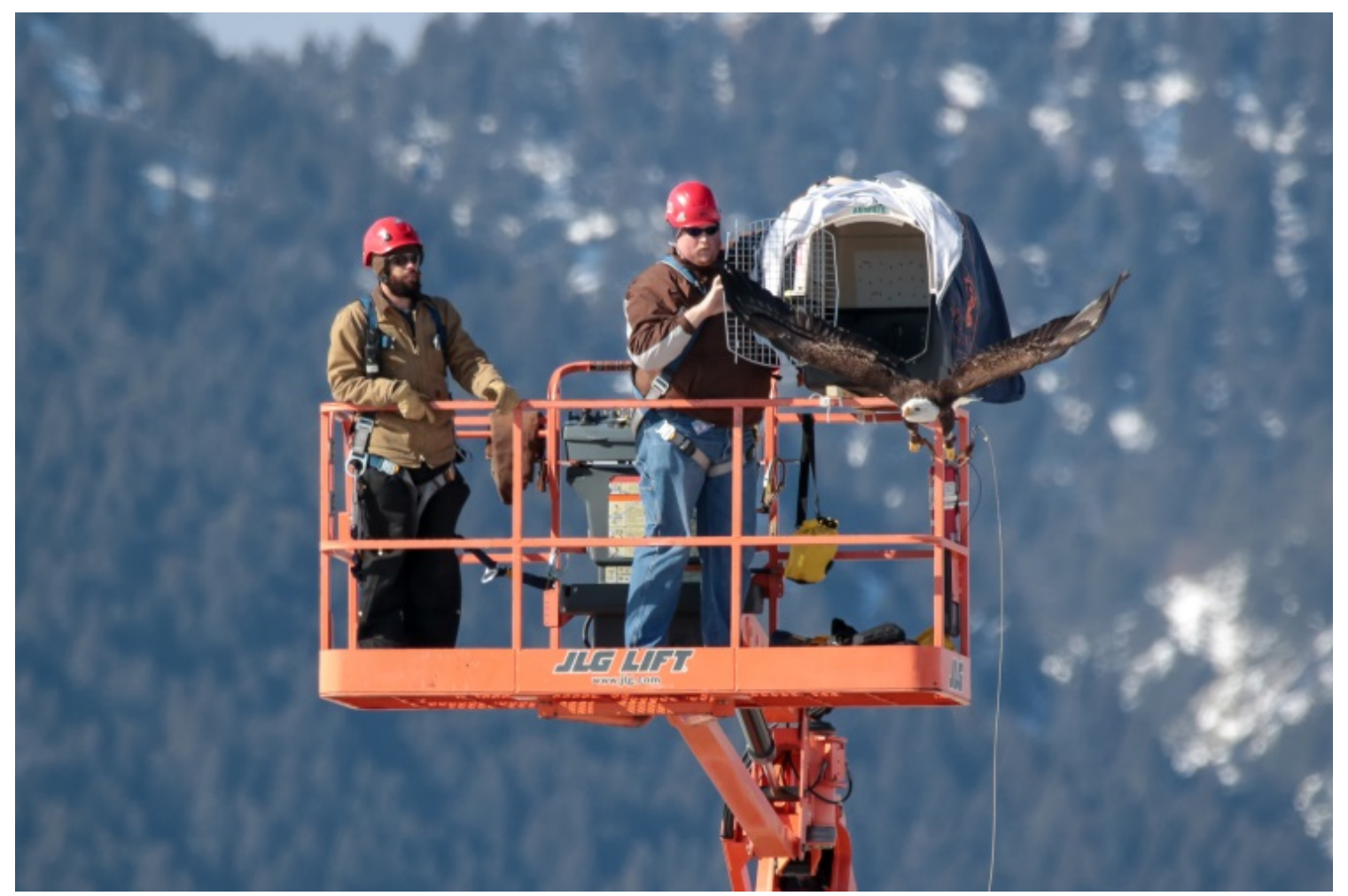

Figure 5. Testing detection systems for bald eagles at the National Wind Technology Center. Photo by Lee Jay Fingersh, NREL 35704 


\section{Breakout Sessions}

Two breakout sessions focused on the current state of detection and deterrent technologies and novel concepts/applications for detecting and minimizing impacts to eagles. Participants were preassigned to either the detection or deterrent discussion for each breakout session, and they reconvened to share key points in a plenary session. The framework for these discussions were based on tables (see Table 1, presented at the end of Section 4.2) that were distributed for review and comment prior to the workshop. Table fields were populated or edited during the discussion process and included:

- Component/idea (the detection or deterrent idea, device or technology)

- Purpose of component (the purpose/intended outcome of a particular detection or deterrent idea, device or technology)

- $\quad R \& D$ opportunity (the specific research and development details and activities to further develop a particular detection or deterrent idea, device or technology)

Other fields that were populated (but not included in Table 1) included known limitations and other notes.

\subsection{Breakout Session 1: Current Technologies}

\subsubsection{Detection/Classification}

Workshop participants discussed information on existing detection technologies that was prepopulated in the tables (see Table 1 for an example). Key suggestions from these breakout session discussions included:

- Focus on areas that can make the biggest difference in terms of reducing eagle mortality. Wind energy does not have a huge market pull to drive hardware development that is unique to the wind energy market. As a result, it may be more cost effective to leverage and modify existing technologies when possible.

- Obtain a suite of tools for testing validation to evaluate the effectiveness of the system.

- Ensure transparent testing and validation.

- Maintain the long-term goal of moving away from tagging and biomonitoring, though these are important validators.

- Consider the natural overlap with technology needs associated with monitoring unmanned aircraft systems (e.g., drones). 


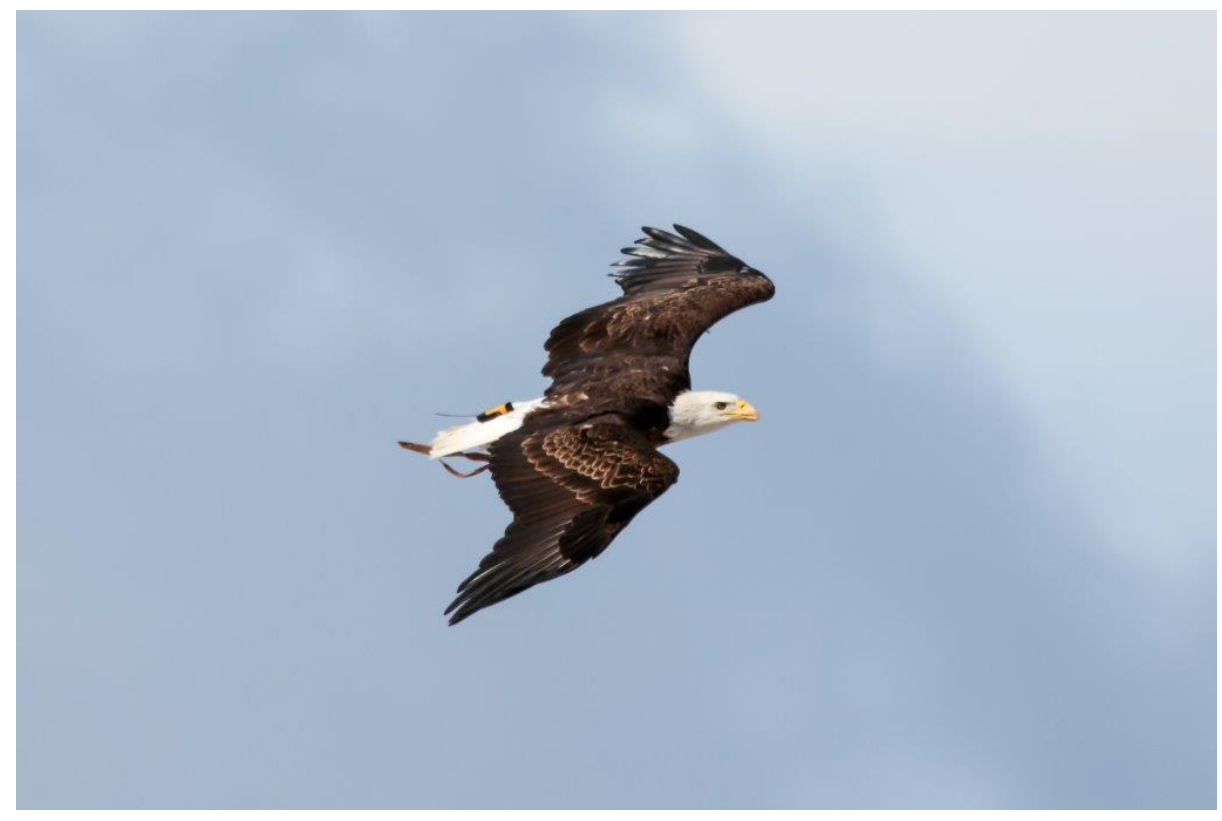

Figure 6. Bald eagle soaring with transmitter. Photo by Lee Jay Fingersh, NREL 35709

- Consider a number of technologies and/or system components, including:

- Solid-state radars with Doppler capabilities. There has been a lot of research funding from other entities, but it has not been specific to eagles and wind turbines. Using this technology may eventually result in the ability to identify species, but a lot more understanding about flight patterns is needed. Current radar technology would need to be combined with other analysis to classify to the species level.

$\bigcirc \quad$ Light detection and ranging (lidar). This technology has a relatively limited area of coverage. Although it might be useful to target species classification, it is not a stand-alone technology. It is not clear whether this technology is costeffective or if information from the U.S. Department of Defense's R\&D program could be made available to help better understand the system's capabilities.

- Visual cameras. Because eagles are active mainly during the day, using visual cameras is a priority for advancing development because they best match the requirements for daytime use. Systems offer a suite of different technologies; however, advances in real-time tracking and data processing are needed. Cost estimates, transparent testing, and validation are also needed.

- Miniaturized computers. Systems comprised of both camera and data processing are needed, but they must be small enough to fit properly on/in a wind turbine.

- Algorithm development. This process requires integrating (decision-tree algorithms) with data coming from different detection technologies.

○ Integrated systems. This requires developing and testing systems that consist of several components. 


\subsubsection{Deterrents}

Workshop participants discussed information on existing deterrent technologies that was prepopulated in the tables (see Table 1 for an example). Key suggestions from these breakout session discussions included:

- Gain a better understanding of the sensory biology (visual and auditory) of eagles as it is linked to cognitive behavior-deterrent versus alert stimuli. Develop technologies based on existing knowledge about eagles' sensory systems (color vision, visual acuity, auditory sweet spots, and so on) and cognitive abilities, and continue to feed information gained about their biology to technology development and testing. Establish a feedback loop among engineers and biologists to speed up the development of technology and increase its success in the field.

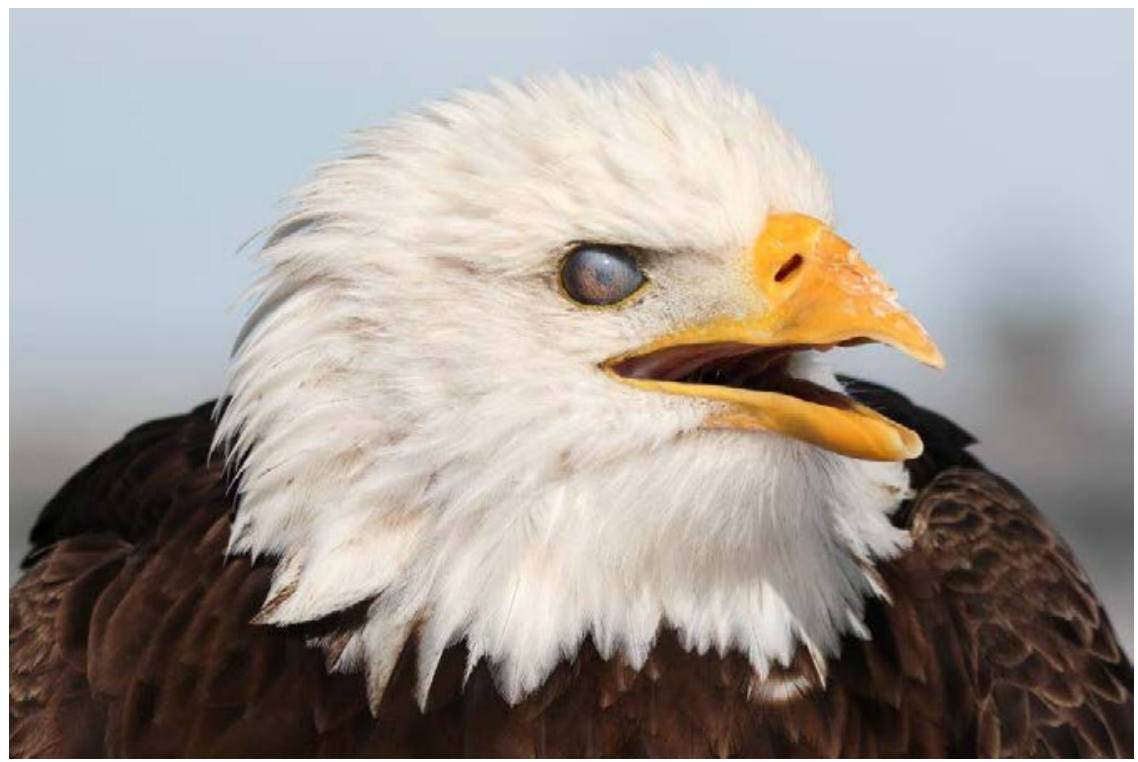

Figure 7. Bald eagle with nictitating membrane. Photo by Lee Jay Fingersh, NREL

- Assess practicality of full site deployment for large facilities; scale will depend on the project-specific needs.

- Investigate the directionality of the technology (broad coverage, which can have unintended impacts, versus a more focused deterrent). It may be possible to use detection devices as a way to focus the deterrent.

- Improve classification/categorization of species. Detection systems need fewer false positives and false negatives.

- Gain a better understanding of habituation. Determine whether habitation is actually occurring or whether the reaction being observed is an artifact of demographic or behavioral characteristics of animals.

- Determine the specific categories of deterrents. For example, compare the use of a masking paradigm (e.g., white noise or veiling light) to other approaches that are not critical for the birds' biology but could be used as vehicles to deliver stressful (i.e., deterrent) stimuli in a focused way. Deterrence might also be focused on prey removal. 
- Research how humans will respond (community acceptance) to visual or acoustic deterrents, understanding that many projects have permit conditions that may limit the sound or light that can be used.

- Assess the threshold at which habitat loss (or any other deterrent) becomes considered nonlethal take.

- Evaluate passive versus active detection-based deterrence measures.

- Identify collision risk-reduction research and how risk-reduction results are measured.

- Ensure a two-pronged approach to look at a biological perspective while, at the same time, developing technology (i.e. get as much biological information needed in the near term to improve current technology). Ensure a feedback loop between biologists and engineers.

\subsubsection{Discussion Summary}

The plenary discussion following the first breakout session touched on four topics: prey management, sensory and cognitive biology, microscale versus macroscale deterrents, and using flight identification systems to track eagles. A general point was made that deterrents, by definition, reduce the availability of (or access to) whatever is drawing an animal to a specific site (in the case of eagles: food, updraft, or nesting sites). By definition, this means making the habitat less suitable; thus, whatever deterrents are used, care must be taken to ensure that longterm impacts do not amount to "disturbance" take.

\subsubsection{Prey Management}

Prey removal has been identified as a potential ACP, but it is not currently accepted as a "scientifically supportable measure." Discussion points during the plenary session included:

- Building a wind site may or may not create or impact existing prey habitat. If applicable, researchers may need a better understanding of how difficult it will be to exclude smaller mammals from an area.

- Removing carcasses and live-trapping/relocating animals to minimize attracting eagles to wind facilities could be an easy way to reduce fatality risk for eagles.

- Other species rely on the same prey base as eagles. This could be a negative or a positive; prey removal could protect other raptors as well as eagles.

\subsubsection{Sensory and Cognitive Biology}

Researchers need live eagles to do this research. Without an understanding of eagles' biological sweet spots, developing sensory deterrents will turn into a trial-and-error exercise that will increase spending and lengthen the time required to develop successful technology. Despite the challenges of harvesting tissue, some members identified solutions to accomplish this to avoid any kind of take (i.e., working with rehabilitation centers that need to euthanize eagles for humane reasons). One of the issues is securing funding for this fundamental step. There are some hurdles to overcome in obtaining live eagles for research purposes. There may be opportunities for the wind industry to partner with and or leverage work from other sectors to learn more about the cognitive biology of bald and golden eagles. Other sectors, for example, could include the U.S. Department of Defense's efforts to minimize eagle collisions with aircraft or chemical manufacturers' efforts to address the impact of rodenticide poisoning on eagles. 
Exploring funding opportunities with the U.S. Department of Energy should also be considered because this issue may not be a top priority for the aforementioned funding sources.

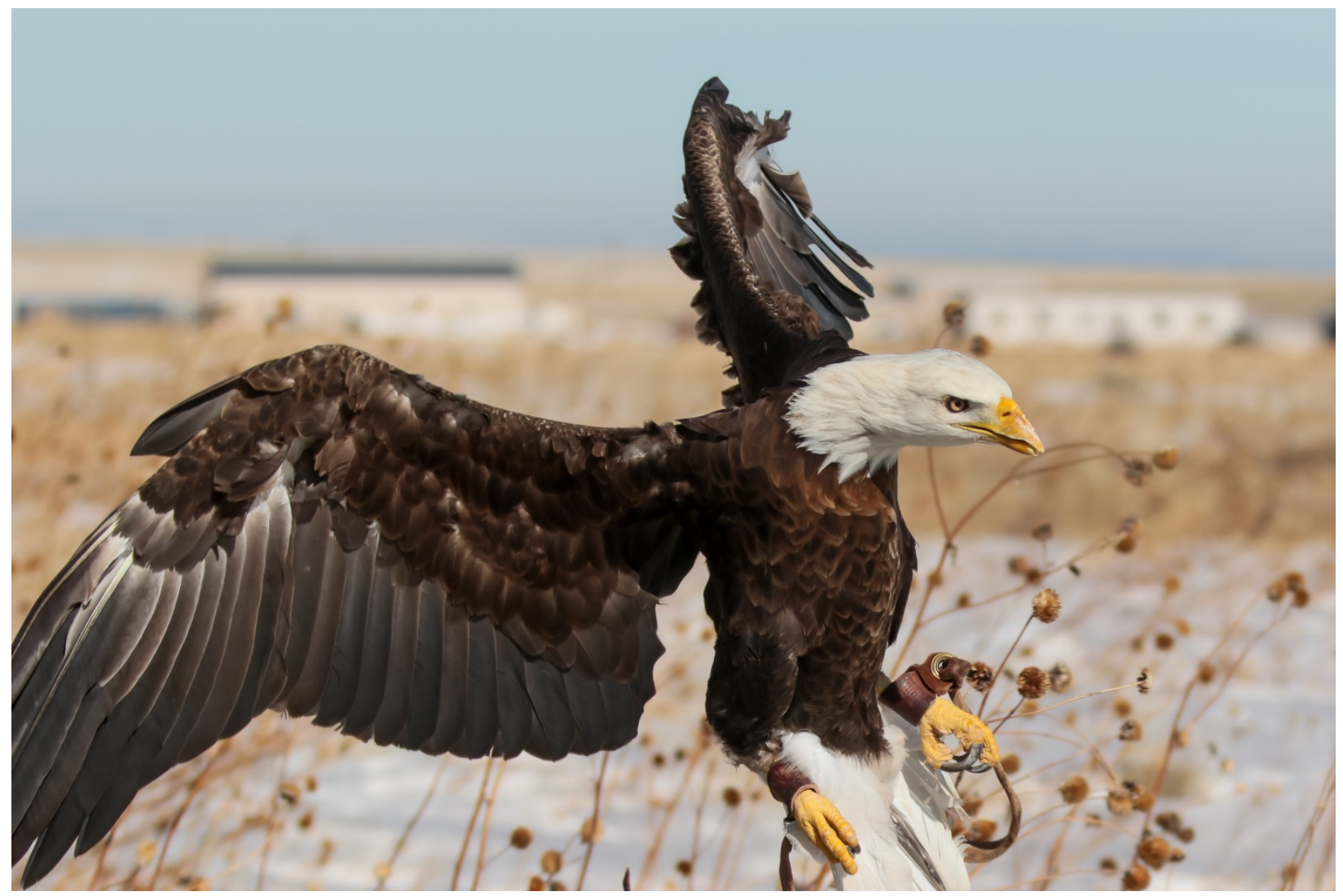

Figure 8. The impressive wing span of Spirit, a 20 -year-old bald eagle. Photo by Lee Jay Fingersh, NREL 35731

\subsubsection{Micro- Versus Macro-Scale Deterrents}

A clear understanding of the scale for which the deterrent is being developed is needed. For example, if an eagle deterrent is used at the facility level (i.e., the macroscale), then it may be different from an eagle deterrent that is used at the turbine level (i.e., microscale). Discussions focused on the differences among the technologies needed for a wind power plant "perimeter wall" compared to those specific to turbines. The group did not coalesce on which option(s) may be better to pursue.

\subsubsection{Flight Identification Systems}

Technology exists to trace the flight patterns and location of eagles. These types of systems are not widely used in the United States, but they are being used in other countries. Discussion points regarding this topic were as follows:

- Cost is prohibitive. Wind industry businesses are operating in a highly competitive economic environment.

- Validation/verification is needed. 
- There is a lack of understanding about what purpose large-scale tracking (using Global Positioning System and other technologies) of eagle activity in and around a wind facility would serve. U.S. agencies, depending on the situation, request monitoring but not tracking.

- The United States has large wind power projects (400 megawatts), whereas European projects tend to be smaller, thus making it easier to track eagle flight patterns within a facility.

- Research has been conducted in the United States on a variety of technologies, but confidentiality (in part because of concerns about prosecution) is a barrier to people talking about the research they are doing.

\subsection{Breakout Session 2: Novel Concepts}

\subsubsection{Detection/Classification}

Workshop participants discussed information on novel detection technologies that was prepopulated in the tables (see Table 1 for an example). Session participants noted that their discussion shifted from detection to deterrence. From these discussions, the following key suggestions were made:

- Use a mosquito detection system (spectral analysis) to detect eagles.

- Deploy low-cost, decentralized systems integrated with individual turbine supervisory control and data acquisition (SCADA) equipment instead of high-cost centralized systems.

- Enhance and create signals that mimic signals sent by birds to better detect the presence of target species.

- Use multiple sensors and a probabilistic approach to detection.

\subsubsection{Deterrent Ideas}

Workshop participants discussed information on novel deterrent technologies that was prepopulated in the tables (see Table 1 for an example). From these discussions, the following key suggestions were made:

- Employ trained crows to harass eagles.

- Reduce the time it takes to curtail wind turbines, thus reducing the lead time needed from detection.

- Use red lasers to scare birds away, and apply laser effects by using light bouncing off feathers, but research would need to be conducted to make sure that lasers do not injure the retinas of golden eagles, which could negatively affect their behavior.

- Employ all kinds of drones, eagle simulators, and other flying devices to scare eagles away from the area.

- Spray grape-seed extract mist from the turbine blade to deter eagles and other birds.

- Use lights/sounds tuned to the eagle visual and auditory sweet spots (which are expected to be different from those of humans). 


\subsubsection{Science-Based Impact-Minimization Solutions}

Session participants observed that having individuals with diverse areas of expertise in the workshop allowed the group to more readily identify research needs. The following key suggestions were made:

- Use turbine or blade-mounted lights or other devices to generate awareness of a turbine and deter birds away from it. These lights should be tuned to eagles' visual systems.

- Couple noise with a visual deterrent.

- Establish visual and auditory sensory thresholds for curtailment. Curtailment may be more appropriate under conditions that diminish eagles' ability to perceive operational turbines. For example, ambient light or background wind noise may put eagles at higher risk of failing to perceive and avoid turbine blades. This can be accomplished by studying the sensory systems of eagles and using currently available modeling tools to estimate eagles' perceptions of the stimuli.

- Determine what it takes to scare an eagle away — possibly by using drones or kites to "defend" the territory or android scarecrows that walk in random patterns around the base of turbines.

- Assess the effectiveness of masking to hide prey on the hunting stimuli of eagles. For example, generate a horizontal plane of light to produce a veiling effect at different heights to reduce the visibility of prey on the ground and thus discourage eagles from hunting in the area (perhaps done in lieu of prey removal).

- Investigate taste or smell as a possible deterrent-for example, by dispersing grape-seed extract mist.

\subsubsection{Discussion Summary}

A number of similar ideas were explored by the two groups during the second breakout session - notably, using drones, kites, or corvids to discourage eagle activity in the risk zone and coupling multiple sensory deterrents (e.g., visual, acoustic, and taste). It was noted that leveraging detection technology to better understand the timing of strikes and types of activities that put eagles at risk would enable researchers and developers to better focus deterrence strategies. 
Table 1. Summary of Technologies Identified During the Workshop

\begin{tabular}{|c|c|c|}
\hline Component & $\begin{array}{l}\text { Purpose of Component/ } \\
\text { Targeted Sensory } \\
\text { Mechanism }\end{array}$ & R\&D Opportunity \\
\hline $\begin{array}{l}\text { Use passive acoustic } \\
\text { monitoring }\end{array}$ & Detection & $\begin{array}{l}\text { Understand whether passive acoustic } \\
\text { monitoring technologies can be effective at } \\
\text { detecting eagles near wind power plants. }\end{array}$ \\
\hline $\begin{array}{l}\text { Research deterrent effects } \\
\text { on humans }\end{array}$ & Social acceptance & $\begin{array}{l}\text { Examine the human impacts/reaction } \\
\text { to/acceptance of the stimuli found to be } \\
\text { most effective at eliciting the desired } \\
\text { deterrent response from eagles. }\end{array}$ \\
\hline Test deterrent placement & Deterrent & $\begin{array}{l}\text { Place deterrents on turbines or within wind } \\
\text { power plants to maximize the efficiency of } \\
\text { the deterrent effect; scale of coverage } \\
\text { questions must also examine the possibility } \\
\text { of habitat loss (take) impacts. }\end{array}$ \\
\hline $\begin{array}{l}\text { Use solid-state Doppler } \\
\text { radar }\end{array}$ & Classification & $\begin{array}{l}\text { Develop speciation capabilities using } \\
\text { techniques such as tracking and flight } \\
\text { patterns/wing beats. }\end{array}$ \\
\hline $\begin{array}{l}\text { Research habituation } \\
\text { effects }\end{array}$ & Deterrent & $\begin{array}{l}\text { Explore habituation (trade-offs among false- } \\
\text { positive identifications, activating deterrents, } \\
\text { and habituation; habituation meaning that } \\
\text { the eagle does not heed the deterrent and } \\
\text { continues into a risk area near a turbine) } \\
\text { and leverage research from other fields } \\
\text { (e.g., aviation). }\end{array}$ \\
\hline Use a SCADA interface & Communication & Integrate detection using a SCADA system. \\
\hline $\begin{array}{l}\text { Improve hardware to } \\
\text { broadcast light or auditory } \\
\text { deterrent }\end{array}$ & Deterrent & $\begin{array}{l}\text { Improve/adapt existing hardware to } \\
\text { broadcast/transmit stimuli. (Research could } \\
\text { occur simultaneously with } \\
\text { physiological/cognitive biology.) }\end{array}$ \\
\hline $\begin{array}{l}\text { Improve understanding of } \\
\text { unintended biological } \\
\text { consequences }\end{array}$ & Deterrent & $\begin{array}{l}\text { Understand unintended biological } \\
\text { consequences for all deterrent systems } \\
\text { proposed. }\end{array}$ \\
\hline Use a masking algorithm & Detection & $\begin{array}{l}\text { Apply pattern recognition from military } \\
\text { space; work to develop techniques to } \\
\text { remove clutter and species of nonissues, } \\
\text { and develop timescale separation of } \\
\text { activities. }\end{array}$ \\
\hline $\begin{array}{l}\text { Use probabilistic models/ } \\
\text { algorithms to predict eagle } \\
\text { presence based on } \\
\text { different factors }\end{array}$ & Prediction of risk & $\begin{array}{l}\text { Conduct research (include biological data), } \\
\text { and use it to develop software that } \\
\text { incorporates models to predict eagle } \\
\text { presence based on different factors-e.g., } \\
\text { prey, weather, topography. }\end{array}$ \\
\hline $\begin{array}{l}\text { Use a decision-tree } \\
\text { algorithm }\end{array}$ & Detect and decide action & $\begin{array}{l}\text { Develop algorithms to provide information } \\
\text { required for permitting and effective use of } \\
\text { deterrents. }\end{array}$ \\
\hline
\end{tabular}




\begin{tabular}{|c|c|c|}
\hline Component & $\begin{array}{l}\text { Purpose of Component/ } \\
\text { Targeted Sensory } \\
\text { Mechanism }\end{array}$ & R\&D Opportunity \\
\hline Use strike-detection tools & Risk/pattern understanding & $\begin{array}{l}\text { Increase understanding of temporal patterns } \\
\text { of bird strikes by developing strike-detection } \\
\text { tools. This includes the ability to classify } \\
\text { species taken. }\end{array}$ \\
\hline $\begin{array}{l}\text { Develop integrated } \\
\text { systems }\end{array}$ & $\begin{array}{l}\text { Detection and deterrent } \\
\text { systems }\end{array}$ & $\begin{array}{l}\text { Develop effective integrated systems with } \\
\text { decision-making software/algorithms. }\end{array}$ \\
\hline $\begin{array}{l}\text { Conduct a literature review } \\
\text { of existing systems and } \\
\text { best practices }\end{array}$ & $\begin{array}{l}\text { All viable sensory } \\
\text { mechanisms and } \\
\text { detection/deterrent systems }\end{array}$ & $\begin{array}{l}\text { Leverage work/research from other fields } \\
\text { outside of wind energy (including other bird } \\
\text { species) to garner a broader understanding } \\
\text { of the known eagle research and leverage } \\
\text { concepts and tools that have been tested } \\
\text { and/or applied successfully. }\end{array}$ \\
\hline $\begin{array}{l}\text { Increase understanding of } \\
\text { eagle perception and } \\
\text { response to stimuli }\end{array}$ & Biology to inform deterrents & $\begin{array}{l}\text { Research the link between cognitive biology } \\
\text { and biology; develop an understanding of } \\
\text { the stimuli that elicit various levels of } \\
\text { response from eagles and how those stimuli } \\
\text { are affected by environmental conditions. }\end{array}$ \\
\hline Use cameras (visual) & Detection, tracking & $\begin{array}{l}\text { Improve tracking capabilities of visual } \\
\text { camera systems in a cost-effective manner. }\end{array}$ \\
\hline $\begin{array}{l}\text { Field-test and validate } \\
\text { existing systems }\end{array}$ & $\begin{array}{l}\text { Detection and deterrent } \\
\text { systems }\end{array}$ & $\begin{array}{l}\text { Validate testing, including peer-reviewed } \\
\text { publications. }\end{array}$ \\
\hline $\begin{array}{l}\text { Use taste-sensory } \\
\text { deterrents }\end{array}$ & Deterrent & $\begin{array}{l}\text { Test the effectiveness of using grape-seed } \\
\text { extract (methyl-anthranilate) mist (irritant), } \\
\text { which has shown promise with other bird } \\
\text { species (distributed by hoses along turbine } \\
\text { blades). }\end{array}$ \\
\hline Redesign turbines & Risk minimization & Redesign turbines to reduce risks to eagles. \\
\hline Veil (hide the ground/prey) & Risk minimization & $\begin{array}{l}\text { Explore various configurations/ideas (light- } \\
\text { emitting diode lights or similar) that could be } \\
\text { deployed on the ground to veil/mask prey } \\
\text { and dissuade eagles from hunting near } \\
\text { turbines. Deployment is a question-i.e., } \\
\text { how can this be effective to an eagle that is } \\
5-600 \mathrm{~m} \text { in the air? Is the veil effective from } \\
\text { many angles? }\end{array}$ \\
\hline $\begin{array}{l}\text { Use hyperspectral } \\
\text { techniques }\end{array}$ & Classification & $\begin{array}{l}\text { Illuminate the subject with a specific type of } \\
\text { light to identify the target species. }\end{array}$ \\
\hline Use laser deterrents & Deterrent & $\begin{array}{l}\text { Evaluate safe and effective laser deterrent } \\
\text { approaches. Red lasers scare waterfowl; } \\
\text { green lasers might also work. }\end{array}$ \\
\hline $\begin{array}{l}\text { Integrate a deterrent into } \\
\text { the turbines }\end{array}$ & Deterrent & $\begin{array}{l}\text { Integrate a deterrent component into the } \\
\text { turbine itself (e.g., compressed air released } \\
\text { when the target is detected at close range). }\end{array}$ \\
\hline
\end{tabular}




\begin{tabular}{|c|c|c|}
\hline Component & $\begin{array}{l}\text { Purpose of Component/ } \\
\text { Targeted Sensory } \\
\text { Mechanism }\end{array}$ & R\&D Opportunity \\
\hline $\begin{array}{l}\text { Create species signatures } \\
\text { to enhance detection }\end{array}$ & Detection & $\begin{array}{l}\text { Increase, augment, or detect novel signals } \\
\text { of eagle presence; potentially use keratin. }\end{array}$ \\
\hline Use lidar & Detection and classification & $\begin{array}{l}\text { Pursue applications at wind power plants; } \\
\text { include technical issues such as area of } \\
\text { coverage and potential to couple with } \\
\text { scanning technology. }\end{array}$ \\
\hline $\begin{array}{l}\text { Use drones to detect, } \\
\text { deter, or lure eagles away } \\
\text { from turbines }\end{array}$ & Detection or deterrent & $\begin{array}{l}\text { Investigate the use of drones for detection } \\
\text { or deterrence. Large artificial eagle drones } \\
\text { may deter other eagles in the area or lure } \\
\text { eagles away from the area. }\end{array}$ \\
\hline $\begin{array}{l}\text { Perform a spectral } \\
\text { analysis }\end{array}$ & Classification & $\begin{array}{l}\text { Apply variable frequency, such as wing-beat } \\
\text { frequency, to identify eagles. }\end{array}$ \\
\hline Use radar & $\begin{array}{l}\text { Detection and possibly } \\
\text { classification }\end{array}$ & $\begin{array}{l}\text { Evaluate new radar design to address the } \\
\text { problem of blade interference-i.e., work } \\
\text { with the turbine rather than against it. }\end{array}$ \\
\hline Use an eagle simulator & Verification & Develop a surrogate eagle to test systems. \\
\hline $\begin{array}{l}\text { Increase the speed at } \\
\text { which curtailment can be } \\
\text { executed }\end{array}$ & Risk minimization & $\begin{array}{l}\text { Increase the ability to stop turbines more } \\
\text { quickly without compromising their integrity. }\end{array}$ \\
\hline $\begin{array}{l}\text { Implement a notification } \\
\text { system that triggers a } \\
\text { deterrent when eagles } \\
\text { cannot perceive turbines }\end{array}$ & $\begin{array}{l}\text { Inform deterrent/mitigation } \\
\text { activation }\end{array}$ & $\begin{array}{l}\text { Collect ambient environmental condition } \\
\text { data to inform probabilistic models that can } \\
\text { determine whether conditions exist and } \\
\text { under which conditions eagles can perceive } \\
\text { turbines. Mount a test camera system on } \\
\text { turbines/meteorological towers to collect } \\
\text { data. }\end{array}$ \\
\hline Use distributed systems & Detection and classification & $\begin{array}{l}\text { Develop a low-cost, distributed system } \\
\text { (instead of a few centralized systems) for } \\
\text { monitoring. }\end{array}$ \\
\hline $\begin{array}{l}\text { Develop novel/advances in } \\
\text { strike-detection } \\
\text { technologies }\end{array}$ & $\begin{array}{l}\text { Verification of } \\
\text { strike/presence }\end{array}$ & $\begin{array}{l}\text { Perform basic research on new detection } \\
\text { methods, from bench testing to field testing. }\end{array}$ \\
\hline
\end{tabular}

During these sessions, other considerations arose related to manufacturing and operations of the wind turbines themselves (Section 4.3) and curtailment (Section 4.4).

\subsection{Wind Turbine Manufacturing and Operations}

As technologies are researched and developed, it is important for developers to work closely with wind turbine manufacturers and operations experts to be sure the ideas will be practical to implement. Consider the following:

- Plant operators have security requirements, and systems that integrate with SCADA must comply with these requirements. 
- Turbine blades are highly engineered, very sensitive to design modifications and are costly to replace or repair. Careful consideration must be made to any blade modifications that could cause structural issues, such as water penetration or ice build-up, which could be problematic or reduce blade efficiency.

\subsection{Curtailment Issues}

There is some debate about the true mechanical, productivity, and or economic implications of curtailment. Nevertheless, the wind industry is sensitive to it. For instance:

- Many wind companies have conducted internal analyses of curtailment costs at multiple cutin speeds to avoid/minimize bat collisions, and lost revenues have been calculated by some project operators to be on the order of millions of dollars per year.

- When curtailing to avoid eagle collisions, detection is crucial. It is very important to avoid false positives; operators do not want to shut down any more frequently than necessary. Curtailment strategies can be integrated with models that predict the conspicuousness of wind turbines based on eagles' visual perspectives (based on sensory biology research). Curtailment could be initiated when ambient light conditions decrease below a given threshold of visibility from eagles' points of view. This strategy could reduce revenue loss even further.

- Lost revenue as a result of downtime during curtailment periods is only one consideration and may be the smallest loss to a wind company. For example, excessive, rapid, emergency shutdown situations presumably cause blades to wear out prematurely. Lost generation when multimegawatt turbines come out of service for repair or replacement is 100 to 1,000 times greater than the cost of lost generation during curtailment events, and replacing a set of turbine blades costs on the order of $\$ 100,000$ per turbine.

\subsection{Additional Solution Refinements}

The group reviewed and made additional refinements to current and novel concepts listed in the tables presented at the workshop.

When refining technology descriptions or categories, participants agreed on the following:

- Impact detection on blades, once developed, should include strike-detection capabilities to classify species taken.

- Blade-mounted, strike-detection instruments are still novel and nonexistent (though a proof of concept has been performed).

- Some of the novel ideas are completely new; whereas others are ready for development.

- Drones could be used in a detection role as well as a deterrent. Although they would perform separate functions, they could be mounted on the same platform.

Additional ideas and comments gleaned from the discussions were as follows:

- Biological data (along with topography, vegetation, and other factors) could be collected to inform probabilistic models/algorithms to predict the presence of eagles based on prey or weather. (European researchers and industry may have some of these data.) 
- It would be beneficial to increase the ability to stop turbines rapidly without compromising the turbine or blade machinery.

- It could be beneficial to determine whether there is a way to have eagles send a remotely identifiable "signature" (e.g., because eagles have significantly more of the protein keratin, a method that identifies its presence remotely could be used to detect the birds).

- Many of the ideas covered in the workshop assumed that eagles habituate to sensory stimuli. We need to understand how rapidly this happens and how we can use stimuli that minimize this potentiality.

- Gathering information from other industries that have tried to deter birds from facilities (e.g., airports) or conducting a literature review might be good options (AWWI may take the initiative to pull this information together). Further comments/discussion on these topics included:

- Solar energy deterrents are for birds in general, not only eagles.

- A lot of research has been conducted to deter blackbirds.

- The aviation industry has published best practices, but much of the literature is site specific and not necessarily peer reviewed.

- The aquaculture industry has been working for decades to keep herons and other birds away from their facilities. 


\section{Participant Prioritization}

Workshop participants were asked about their individual impressions of the relative priority of each of the existing and novel ideas that were discussed. Criteria included:

- Likelihood of success - i.e., probability that conducting R\&D will yield useful, constructive results

- Ultimate affordability

- Ultimate efficacy

- Cost of R\&D

- Length of time to commercial application.

The purpose of this exercise was to provide workshop participants with an opportunity to share their individual recommendations as influenced by their personal experiences, areas of expertise, and levels of knowledge on the topic. It was emphasized that this was an exercise, not a plan for R\&D.

Participants placed a very high level of emphasis on existing systems, including ideas that involve more independent field tests and validations of these systems. Improvements could include, but are not limited to, advancing the capability of visual cameras to detect eagles at wind power plants. An in-depth literature review of existing systems and best practices could also be useful.

In addition, participants placed a similar level of interest on gaining a better understanding of eagles' perceptions and responses to stimuli, which will be critical to developing effective deterrent systems. This interest ties to the information presented by both Fernandez-Juricic and Lucas on eagles' physiological considerations, wherein attendees learned that there is a gap in our understanding of the visual systems of golden eagles that will need to be addressed to develop effective deterrents, and developing an effective auditory deterrent requires knowing more than the minimum sound level eagles can hear. Researchers want to understand how it might be possible to make turbines more visually conspicuous for eagles and how eagles respond to louder sounds, different tones, amplitude modulations, and rapid frequency sweeps. Notably, researchers must keep in mind that not every bird finds the same stimulus equally deterring.

Participants also placed a high level of emphasis (though slightly less than that placed on identifying and testing existing systems) on integrated systems, including integration with algorithms that will help viewers of optic data make operational decisions as well as gain a better understanding of when and under what conditions bird strikes occur. Algorithms would allow researchers to apply pattern recognition to dynamic phenomena (e.g., sky, clouds, turbine blades, predator/prey behavior) to predict conditions when bird strikes could occur.

Less emphasis was placed on assessing secondary impacts, including habituation. Specifically, it was suggested that until the core detection and deterrent systems are refined/defined, secondary impacts are less important. 
Also given lower prioritization were studying deterrent placements, improving passive acoustic monitoring, further developing solid-state Doppler radars and SCADA interfaces, and studying deterrent effects on humans. Here, too, participants suggested that developing and refining detection and deterrent systems should be the focus prior to addressing these other considerations. For example, because eagles do not vocalize very often, collecting auditory information within wind resource areas may not be useful in adequately predicting future eagle activity. As a result, passive acoustic monitoring is not a high priority. In terms of understanding the effects of deterrents on humans, developing appropriate approaches that will successfully deter eagles is deemed more critical than gaining an understanding of the secondary impacts of these approaches. 


\section{Summary and Next Steps}

\subsection{Key Elements Needed to Conduct Research}

Workshop participants were asked to identify the key elements needed to move technologies forward, which can be accomplished by asking the following questions:

- For existing eagle detection and deterrent technologies, what essential issues need to be resolved to execute successful research?

- For new technology concepts or novel applications of technologies not yet used to detect and deter eagles, what essential elements are needed to prove the concepts or novel applications?

Key issues and opportunities discussed included:

- Funding. Field tests are expensive.

- Access to eagles. Researchers need to communicate and coordinate with groups who have eagles (e.g., injured or otherwise nonreleasable animals or their organs) that can be used to conduct laboratory tests.

- Level of protection from liability or litigation. Conducting field tests at wind energy projects with a lot of eagle activity may result in a high risk of take; therefore, the test sponsor needs to be protected from liability by having an eagle take permit, through a plea agreement or settlement decision, or other mechanism. Several key issues related to this topic were discussed, including:

- A number of these technologies could be tested without putting eagles at risk.

- The USFWS recognizes the problem for eagle-related research. The BGEPA, per the 2009 USFWS regulations, does allow for permitting of nonpurposeful (i.e., incidental) take of eagles as long as such take meets the standards in the 2009 regulations; however, the timeline for getting a permit can be challenging.

○ The USFWS analyzes applications for scientific take permits. Applications for take permits are, or are being, submitted as part of settlement agreements (e.g., Wyoming), for scientific permits, or for eagle programmatic take permits for wind facilities. Settlement agreements are probably the fastest way to get a pool of high eagle-use sites where research can be conducted, but getting these types of agreements is challenging. Settlement agreements offer absolution for historic take, which includes restitution.

○ Upfront communication with decision-makers and other stakeholders, as appropriate, regarding testing locations is important. Coordinated testing among a broad suite of landscapes, habitats, and so on is needed.

○ Tests should be scaled up gradually to avoid incidental take and assume risk slowly.

- Other mechanisms for conducting eagle research. Options are limited, which creates a disincentive to conduct research. One option may be to use a surrogate species to conduct research, but acceptance of related data is unclear at this time. 
- Need for interdisciplinary teams. Teams could include biologists, quantitative ecologists, software engineers, and so on. The interdisciplinary team should:

- Share test protocols as well as data with all groups.

○ Validate field methods.

- Ensure good dialogue among engineers and biologists; engineers can offer insights into what is viable from a technological standpoint, and biologists can focus on answering questions related to sensory perception/response.

- Share data from field tests so that benchmark data sets can be created (especially considering that automation is a big priority to eliminate the need for biomonitors (people).

- Need for greater clarity. Specifically, there is a need to clarify what is required to meet the ACP standard. Discussion around this topic included the following:

- Gain a better understanding of what will be considered an acceptable ACP. An $A C P$ is defined as a "scientifically supportable method" (generally as recognized through publication in a peer-reviewed journal). The USFWS is currently engaged in a regulation review process; thus, details have not yet been made public.

- Determine how effective a treatment needs to be to meet the standard. The criterion is to "minimize to the maximum extent achievable"; therefore, it is not necessary to show that an ACP reduces take, only that "everything has been done to minimize risk to the maximum extent practicable."

- Define how much money needs to be spent to achieve specific results. The "maximum extent practicable" does include cost considerations. Using a standardized methodology to evaluate eagle behavior before and after deploying a deterrent technology could thereby allow data to be aggregated from multiple facilities to overcome a small sample size.

\subsection{Next Steps}

Next steps will include disseminating information through these proceedings and webinars. In addition, a more thorough literature review of existing and emerging technologies will be conducted that is similar to those for other renewable technologies, such as solar energy. Ideally, a follow-on forum will be convened to continue this critical dialogue and encourage the development of wind energy projects in a manner that minimizes impacts to eagles and other wildlife. 


\section{Bibliography}

Aschwanden, Janine, Sandro Wanner, and Felix Liechti. 2015. Investigation on the Effectivity of Bat and Bird Detection at a Wind Turbine: Final Report Bird Detection (Technical Report).

Sempach, Switzerland: Schweizerische

Vogelwarte. http://www.dtbird.com/images/Downloads/FinalReport_DTBird_VoWa_with_DTB ird notes.pdf

Bevanger, Kjetil, et al. 2010. Pre-and Post-Construction Studies of Conflicts between Birds and Wind Turbines in Coastal Norway (Bird-Wind): Report on Findings 2007-2010 (Technical Report). Trondheim, Norway: Norwegian Institute for Nature Research. http://www.nina.no/archive/nina/PppBasePdf/rapport\%5C2010\%5C620.pdf.

Bowden, Tim, Erik Olson, Nathan Rathbun, Daniel Nolfi, Rebecca Horton, and David Larson. 2011. Great Lakes Avian Radar Technical Report Huron and Oceana Counties, MI (Technical Report). Bloomington, $\mathrm{MN}$ :

USFWS. http://www.fws.gov/radar/documents/AvianRadarTechnicalReportFall2011.pdf.

Brabant, R., L. Vigin, E.W.M. Stienen, N. Vanerman, and S. Degraer. 2012. "Radar Research on the Impact of Offshore Wind Farms on Birds: Preparing to Go Offshore." In Offshore Wind Farms in the Belgian Part of the North Sea: Heading for an Understanding of Environmental Impacts, edited by Steven Degraer, Robin Brabant, and Bob Rumes, 111-126. Brussels, Belgium: Royal Belgian Institute of Natural Sciences. http://tethys.pnnl.gov/sites/default/files/publications/Degraer_et_al 2012.pdf.

California Energy Commission. 2015. "List Servers (Automated Email Groups) Hosted by the California Energy Commission.” http://www.energy.ca.gov/listservers/.

Cullinan, Valerie I., Shari Matzner, and Corey A. Duberstein. 2015. "Classification of Birds and Bats using flight tracks." Ecological Informatics 27:55-

63. http://www.sciencedirect.com/science/article/pii/S1574954115000692.

\section{Deepwater Wind's Block Island Wind Farm}

Documents: http://dwwind.com/documents/?projects=block-island-wind-farm, including:

- Tetra Tech, Inc. 2012. Block Island Wind Farm Block Island Transmission System. Environmental Report/Construction and Operations Plan (Technical Report). Providence, RI: Deepwater Wind. http://dwwind.com/wp-content/uploads/2014/08/EnvironmentalReport.pdf.

- Svedlow, Aaron B., Lauren Gilpatrick, Brad Agius, Margo Andrews, and Paul Myers. 2012. Appendix O: Pre-Construction Avian and Bat Survey Report (Technical Report). Providence, RI: Deepwater Wind. http://www.offshorewindhub.org/sites/default/files/resources/deepwater 9-272012 biwfbitserappendixo.pdf. 
Fijn, R.C., A. Gyimesi, M.P. Collier, D. Beuker, S. Dirksen, and K.L. Krijgsveld. 2012. Flight Patterns of Birds at Offshore Gas Platform K14: Flight Intensity, Flight Altitudes, and Species Composition in Comparison to OWEZ (Technical Report). IJmuiden, The Netherlands: Nordzee Wind. http://www.noordzeewind.nl/wpcontent/uploads/2012/11/OWEZ_R_232_T1_20120523 fluxes_far_offshore.pdf.

Fijn, Ruben C., Karen Krijgsveld, Martin J.M. Poot, and Sjoerd Dirksen. 2015. "Bird Movements at Rotor Heights Measured Continuously with Vertical Radar at a Dutch Offshore Wind Farm." IBIS 157:558-566. http://onlinelibrary.wiley.com/doi/10.1111/ibi.12259/abstract.

Hanagasioglu, Mehmet, Janine Aschwanden, Fabio Bontadina, and Marcos de la Puente Nilsson. 2015. Investigation of the Effectiveness of Bat and Bird Detection of the DTBat and DTBird Systems at Calandawind Turbine (Technical Report). Bern, Switzerland: Swiss Federal Office of Energy. http://www.bfe.admin.ch/php/modules/enet/streamfile.php?file $=000000011272$.pdf\&na $\underline{m e}=000000291031$.

Krijgsveld, K.L., et al. 2011. Effect Studies Offshore Wind Farm Egmond aan Zee: Final Report on Fluxes, Flight Altitudes and Behaviour of Flying Birds (Technical Report). IJmuiden, The Netherlands: Nordzee Wind. http://www.noordzeewind.nl/wpcontent/uploads/2012/03/OWEZ_R_231_T1_20111114_2_fluxflight.pdf.

Lindeboom, H.J., H.J. Kouwenhoven, M.J.N., Bergman, S. Bouma, S. Brasseur, R. Daan, R.C. Fijn, D. de Haan, S. Dirksen, and R. van Hal. 2011. "Short-Term Ecological Effects of an Offshore Wind Farm in the Dutch Coastal Zone: A Compilation." Environmental Research Letters 6(3). http://iopscience.iop.org/article/10.1088/17489326/6/3/035101? fromSearchPage=true.

Liquen Consultoría Ambiental. (undated). "DTBird Fact Sheet Collision Avoidance \& Stop Control Modules

Onshore." http://www.dtbird.com/images/Downloads/DTBird Fact Sheet Bird Collision Prob ability.pdf.

Matzner, Shari, Valerie I. Cullinan, and Corey A. Duberstein. 2015. "Two-Dimensional Thermal Video Analysis of Offshore Bird and Bat Flight." Ecological Informatics 30:2028. http://www.sciencedirect.com/science/article/pii/S1574954115001478.

May, Roel, Øyvind Hamre, Roald Vang, and Torgeir Nygård. 2012. Evaluation of the DTBird Video-System at the Smola Wind-Power Plant: Detection Capabilities for Capturing NearTurbine Avian Behavior (Technical Report). Trondheim, Norway: Norwegian Institute for Nature

Research. http://www.dtbird.com/images/Downloads/NINA_report 910 with_Dtbird_notes.pdf.

Nilsson, Marcos de la Puente. 2015. DTBird System Pilot Installation-Service Results of Migratory Period: Autumn 2014. Haldenstein, Switzerland:

Calandawind/Interwind. http://www.dtbird.com/images/Downloads/DTBird System Pilot instal ation_Calandawind_Service_Results.pdf. 
NordzeeWind. 2015. "Knowledge: Reports \&

Data." http://www.noordzeewind.nl/en/knowledge/reportsdata/.

Plonczkier, Pawel, and Ian Simms. 2012. "Radar Monitoring of Migrating Pink-Footed Geese: Behavioural Responses to Offshore Wind Farm Development." Journal of Applied Ecology 49(5):1,187-1,194. http://onlinelibrary.wiley.com/doi/10.1111/j.1365-2664.2012.02181.x/full.

Rosa, Isabel M.D., Ana Teresa Marques, Gustavo Palminha, Hugo Costa, Miguel Mascarenhas, Carlos Fonseca, and Joana Bernardino. 2016. "Classification Success of Six Machine Learning Algorithms in Radar Ornithology." IBIS 158:28-

42. http://onlinelibrary.wiley.com/doi/10.1111/ibi.12333/abstract.

Swaddle, J., D. Moseley, M. Hinders, and E.P. Smith. 2015. "A Sonic Net Excludes Birds from an Airfield: Implications for Reducing Bird Strike and Crop Losses." Ecological Applications. http://onlinelibrary.wiley.com/doi/10.1890/15-0829/full.

USFWS. 2013. Eagle Conservation Plan Guidance: Module 1-Land-Based Wind Energy Version

2. http://www.fws.gov/migratorybirds/pdf/management/eagleconservationplanguidance.pdf.

USFWS. 2016. "Monitoring Migration Along the Great Lakes: Tracking Bird and Bat Migration Along the Great Lakes Shoreline to Guide Wind Energy Development and Reduce the Risk to Migrants." Last modified January 5. http://www.fws.gov/radar/.

Western EcoSystems Technology, Inc. 2014. Review of Potential Bird Deterrent Strategies for Large Scale Solar Facilities. Oakland, CA: Palen Solar Holdings, LLC.

Western EcoSystems Technology, Inc., and Duke Energy Renewables. 2014. Review of Potential Bird Detection and Deterrent Strategies. Laramie, WY.

Willmott, Julia Robinson, Greg M. Forcey, and Lauren A. Hooton. 2015. "Developing an Automated Risk Management Tool to Minimize Bird and Bat Mortality at Wind Facilities." Ambio 44:557-571. http://link.springer.com/article/10.1007/s13280-015-0707-z/fulltext.html. 


\section{Appendix A: Workshop Agenda}

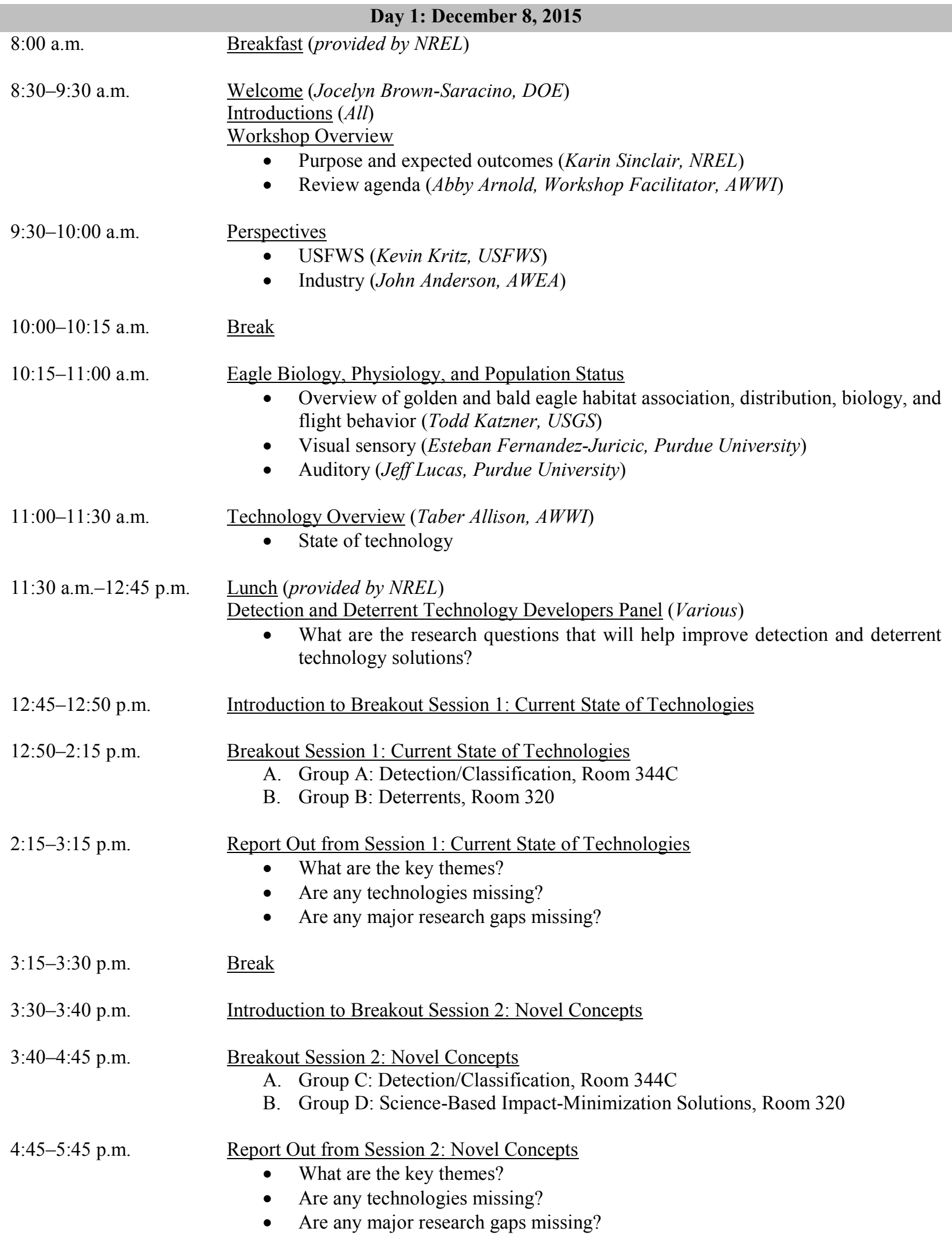


5:45-6:00 p.m.

6:00 p.m.

8:00 a.m.
8:30-9:30 a.m.
9:30-10:30 a.m.
10:30-11:00 a.m.
11:00 a.m.-12:00 p.m.

11:00 a.m.-12:00 p.m.

2:00-1:00 p.m.

1:00-1:45 p.m.

1:45 p.m.

2:30-4:30 p.m.

\section{Day 2: December 9, 2015}

Breakfast (provided by NREL)

Day 1 Recap

- Overnight reflections from participants

- Review tables (Raphael Tisch, DOE)

Prioritize R\&D Opportunities (Polling and Facilitate Discussion of Poll Results)

- Current technologies

- Novel and emerging technologies

Break

Identify the Elements Needed to Carry Out Priority Research Opportunities (Facilitated Discussion)

- For existing eagle detection and deterrent technologies, what essential ingredients are needed to execute successful research?

- For new technology concepts or novel applications of technologies not yet used for eagle detection or deterrence, what essential elements are needed to prove the concepts or novel applications?

Lunch (provided by NREL)

Conclusions and Next Steps (Karin Sinclair, NREL)

$\underline{\text { Adjourn }}$

Optional Tour: National Wind Technology Center

- 18200 CO-128, Boulder, CO, 80303 


\section{Appendix B: Workshop Participants}

\begin{tabular}{|c|c|}
\hline Name & Organization \\
\hline Roberto Albertani & Oregon State University \\
\hline Taber Allison $^{a}$ & American Wind Wildlife Institute \\
\hline John Anderson & American Wind Energy Association \\
\hline Abby Arnold & American Wind Wildlife Institute \\
\hline Mike Azeka & EDF Renewables \\
\hline Heather Beeler ${ }^{a}$ & U.S. Fish and Wildlife Service \\
\hline Rene Braud & Pattern Energy \\
\hline Jocelyn Brown-Saracino & U.S. Department of Energy \\
\hline Steven Brunton & University of Washington \\
\hline Aaron Coppage & Boulder Imaging \\
\hline Karyn Coppinger & Invenergy \\
\hline Dave Cowan & SunEdison \\
\hline Elise DeGeorge & National Renewable Energy Laboratory \\
\hline Corey Duberstein & Pacific Northwest National Laboratory \\
\hline Stephanie Eatinger & Los Angeles Department of Water and Power \\
\hline Samantha Eaves & U.S. Department of Energy \\
\hline Daly Edmunds & National Audubon Society \\
\hline Wally Erickson & Western EcoSystems Technologies \\
\hline Ian Evans & American Wind Wildlife Institute \\
\hline Esteban Fernandez-Juricic $^{a}$ & Purdue University \\
\hline Lee Jay Fingersh & National Renewable Energy Laboratory \\
\hline Greg Forcey & Normandeau Associates \\
\hline Andrew Gilbert & Biodiversity Research Institute \\
\hline Patrick Gilman & U.S. Department of Energy \\
\hline Tim Hayes & Duke Energy \\
\hline Tom Hiester & RES Americas \\
\hline Carlos Jorquera & Boulder Imaging \\
\hline Todd Katzner $^{a}$ & U.S. Geological Survey \\
\hline Kevin Kritz & U.S. Fish and Wildlife Service \\
\hline Jim Lindsay & NextEra Energy \\
\hline Jeff Lucas & Purdue University \\
\hline Kevin Martin & Terra-Gen \\
\hline Shari Matzner & Pacific Northwest National Laboratory \\
\hline Brian Millsap & U.S. Fish and Wildlife Service \\
\hline
\end{tabular}




\begin{tabular}{|c|c|}
\hline Name & Organization \\
\hline Laura Nagy & Iberdrola Renewables \\
\hline Kaj Skov Nielson & Siemens \\
\hline Marcos de la Puente Nilsson & DTBird \\
\hline Ben Quinn & Vestas \\
\hline Jerry Roppe & Iberdrola Renewables \\
\hline Stacy Ryan & SRC, Inc. \\
\hline Joy Page & Defenders \\
\hline Karin Sinclair & National Renewable Energy Laboratory \\
\hline Jeff Smith & HT Harvey \\
\hline Andy Stewart ${ }^{a}$ & University of Washington \\
\hline David Stoms & California Energy Commission \\
\hline Rob Suryan & Oregon State University \\
\hline Robert Thresher & National Renewable Energy Laboratory \\
\hline Raphael Tisch & New West Technologies \\
\hline Karen Voltura, PhD & DeTect, Inc \\
\hline Christopher Wasser & Renewable NRG Systems \\
\hline Bethany Straw & National Renewable Energy Laboratory \\
\hline Samantha Rooney & National Renewable Energy Laboratory \\
\hline Susan Savitt Schwartz & Notetaking Services \\
\hline Katie Umekubo ${ }^{\text {b }}$ & Natural Resources Defense Council \\
\hline Mark Roll ${ }^{b}$ & AECOM \\
\hline Michael Shirmacher ${ }^{b}$ & Bat Conservation International \\
\hline Erin Riley ${ }^{\mathrm{b}}$ & AECOM \\
\hline Reinhard Moratz & University of Maine \\
\hline Julia Willmott $^{\mathrm{b}}$ & Normandeau Associates \\
\hline Greg Aldrich $^{b}$ & Duke Energy \\
\hline Patrick Gilman ${ }^{\mathrm{b}}$ & U.S. Department of Energy \\
\hline Erin Delawalla ${ }^{\mathrm{b}}$ & Invenergy \\
\hline
\end{tabular}

${ }^{a}$ These attendees supported event development as members of the steering committee.

${ }^{\mathrm{b}}$ These attendees participated remotely via a Web meeting. 


\section{Appendix C: Regulatory and Industry Perspectives Eagle Act Regulations and the Regulatory Framework for Detect and Deter Technologies}

By Kevin Kritz, U.S. Fish and Wildlife Service

The Bald and Golden Eagle Protection Act establishes a prohibition against the "take" of these birds, which includes killing or disturbing them. To disturb is defined as to "agitate or bother to a degree that causes or is likely to cause injury, decrease in productivity by substantially interfering with normal breeding, feeding, sheltering, or nest abandonment."

The 2009 Eagle Permit Rule provided a mechanism for the U.S. Department of Interior's U.S. Fish and Wildlife Service (USFWS) to authorize nonpurposeful (i.e., "incidental") take under certain circumstances. Two permit types are available under this rule: 22.26 covers the nonpurposeful, unavoidable take of eagles; and 22.27 provides for the intentional take of an (typically inactive) eagle nest. There are individual, or "standard," and programmatic permit types; the latter is most relevant to wind energy facilities where the possibility of take is ongoing during a period of time, and the specific time and amount of take are unknown.

The 2013 Eagle Conservation Plan Guidance document provides a regulatory framework for assessing and mitigating risk to eagles at land-based wind energy sites by developing eagle conservation plans that incorporate advanced conservation practices (ACPs) to avoid and minimize take. Authorized take must be unavoidable after the implementation of ACPs, which are defined as "scientifically supportable measures" that are approved by the USFWS and represent the "best available techniques" to reduce both eagle disturbance take and ongoing mortality. Unavoidable take must also be consistent with the eagle preservation standard- that is, the goal of increasing or maintaining stable breeding populations.

To date, no conservation measures have been scientifically demonstrated to reduce eagle disturbance and blade-strike mortality at wind projects; therefore, the USFWS has not approved any ACPs for these types of projects. The USFWS envisions working with industry to develop ACPs for wind projects as part of an adaptive management regime and comprehensive research program designed to obtain the scientific information needed to issue programmatic eagle take permits.

The legal conundrum to this approach is that it is difficult to get a permit without proven ACPs, and proposed ACPs cannot be proven without scientific evaluation under operational conditions. Deploying experimental detection/deterrence technologies at an operating wind facility without a take permit puts the company and partnering agencies at legal risk if an eagle is killed and that facility is not covered under a private legal settlement with the U.S. Department of Justice. Testing detection and deterrence technologies must be done via all processes and measures associated with a programmatic eagle take permit. Also, given that using deterrent technologies could result in disturbance take at wind facilities, a separate eagle disturbance take permit authorization should be pursued - especially for wind facilities near eagle nests or communal roosts. 
In such a scenario, proposed detection/deterrence technologies would be implemented at operating wind facilities with an eagle take permit on an experimental basis. These experimental ACPs would need to be scientifically evaluated for effectiveness, and based on the results of these studies they could be modified as part of an adaptive management process. This approach would provide the needed scientific information for the future establishment of formal ACPs while allowing wind energy projects to move forward. If the testing results indicate that the effectiveness of these experimental ACPs sufficiently reduces eagle take, the USFWS would approve them and require them as a basis for issuing future eagle take permits at wind projects.

\section{Eagle Populations}

By Brian Millsap, U.S. Fish and Wildlife Service

Bald eagle populations have been increasing following the ban on DDT, and they are now healthy and resilient; therefore, at this time the take of a bald eagle up to a point is a legal issue, not a biological concern. A take rate for bald eagles that is greater than $8 \%$ (less in some places, such as the Southwest) would also be a population concern. For golden eagles, the situation is very different. Current populations can sustain a take rate of up to $10 \%$, but existing levels from all sources are already at or exceed $10 \%$, with overharvesting on the order of 1,000 golden eagles per year; therefore, it is critical to minimize fatalities of golden eagles. Programmatic take permits for wind energy must include mortality offsets from other sources. Based on the best available data from the USFWS, starvation kills the most eagles (mostly juveniles, followed by poisoning and shooting. The USFWS suspects that a lot of the poisonings are from rodenticides, but not all are (some are from direct poisoned baiting), and many cannot be diagnosed to the exact compound. Illegal shooting and secondary poisoning from rodenticides are more difficult to mitigate than electrocutions, for which there are proven mitigation measures.

\section{Wind Industry Perspective}

\section{By John Anderson, American Wind Energy Association}

The wind industry needs a suite of eagle avoidance and minimization mechanisms that are effective at detecting and deterring eagles and have known repair and replacement costs and manageable operational constraints. From the legal standpoint, greater certainty is needed about what is acceptable from the USFWS. There is a need to think more creatively than "if you're going to take an eagle, you need to get a take permit." From the legal certainty standpoint, the issue is twofold. First, to get this research and development work done quickly, the industry (and the U.S. Department of Energy) cannot wait for years (in nearly 6 years, the service has issued one take permit) for the service to authorize the potential take of eagles at facilities hosting the research. Because the need to test technologies at facilities has a higher than anticipated likelihood of taking eagles, in situations where nonlethal testing (not at wind power plants) could result in harming and harassing eagles, and where public funding would likely require public access or reporting of data, there needs to be some mechanism to provide liability relief. Whether that is through a research permit, memorandum of understanding, etc., does not really matter as long as the liability issue is addressed.

Second, as noted there is a need for longer-term certainty for wind facilities involved in testing, when they might be hosting research for a year or two, and they might identify themselves as a 
high-risk site, so they will need legal certainty until a final permit is issued; this strategy could be a bridge between research and permit issuance. The easiest way to handle this is likely for the U.S. Department of Interior's USFWS Office of Legal Enforcement to state that projects that are voluntarily participating in research will not be enforced against as long as they are in the process of obtaining an eagle take permit and taking steps to avoid losses in the interim. Without sufficiently addressing these issues, as noted, lenders will likely be uncomfortable or unwilling to close project financing until a permit is issued or there is something in writing showing that the developer will be held harmless if a take occurs.

From a practical standpoint, detection and deterrent technologies involve many operational unknowns. Even if a technology proves promising, it must be scaled up to accommodate a project that spans thousands of acres. Current devices have to be mounted on each turbine, so costs would need to come down a lot for this to be practical. Other approaches may be to determine which turbines have higher risk. In addition, an understanding of how the technologies impact the performance (operations and maintenance) of the turbines is needed. It is relatively easy to estimate the operational impacts of raising cut-in speeds, but this does not appear to be as appropriate a solution for eagles as it is for bats.

Technologies need to be easily implementable and capable of being integrated into large-scale energy facilities without incurring untenable operational impacts. Detection systems that can reliably identify targets in a split second are needed - from far enough away that there is time to safely shut down turbines, if that is the solution. Current systems are cost-prohibitive at the project level and not necessarily satisfactory from the perspective of the USFWS.

For each proposed solution, several key questions must be considered:

- Does the solution work? Does it reduce take?

- What level of take reduction is required for the measure to qualify as an advanced conservation practice (ACP)? When can developers count on some form of regulatory acceptance? The wind industry needs to expedite the understanding of whether a technological solution meets regulatory criteria. (It would be useful to have an interagency memorandum of understanding about what it takes for a technological solution to qualify as an ACP.)

- What are the operational costs of implementing the technological solution? Any solution needs to evaluate the cost of installing, repairing, and replacing any technology against the status quo of paying for monitors (if used) and the loss of energy associated with operational adjustments (e.g., raised cut-in speeds, full curtailment), wear and tear, and so on.

Meeting this challenge requires a coordinated, well-funded, comprehensive effort that involves technology developers, biologists, the wind industry, and regulators. Wind energy is the single greatest, lowest cost, most easily deployable way to reduce carbon emissions, and climate change is the single greatest threat not only to eagles but to other wildlife. 


\section{Appendix D: Biological and Physiological Perspectives}

\section{Overview of Golden and Bald Eagle Habitat Association, Distribution, Biology, and Flight Behavior}

By Todd Katzner, U.S. Geological Survey

Bald and golden eagles have a widespread distribution, with many similarities and some differences between the two species in terms of habitat, sensitivity to human disturbances and nesting cycles, diet, demography, and flight behavior. As pointed out by Brian Millsap, bald eagle populations have made a strong comeback since DDT was banned; golden eagle populations are stable or slowly declining; and both species face a large suite of anthropogenic threats, notably electrocution, illegal shooting, and secondary poisoning via rodenticides (both species scavenge extensively, especially during the winter months).

Both species of eagle are long-lived, form long-lasting pair bonds, begin breeding between 5-7 years of age, do not breed every year, and produce 1-3 chicks per attempt. Eagles are soaring specialists; flapping is rare. The birds use either thermals or orographic (or deflected) updrafts to subsidize flight. Orographic updraft occurs only at low altitudes; thus, eagles using it are closer to the ground. Topography is important in looking at eagle flight behavior and distribution, especially for golden eagles.

In thinking about wind development's impact on eagles, keep in mind that eagles need food, updraft, and nesting sites. Eagle mortality at wind sites that intersect significantly with one or more of these factors can be high (e.g., Smøla, Norway; Altamont, California; Wyoming).

\section{Visual and Auditory Sensory Characteristics of Eagles}

\section{Visual Systems}

By Esteban Fernández-Juricic, Purdue University

Birds rely heavily on their visual organs, yet they collide with wind turbines, which are visually conspicuous to humans but not necessarily to birds. Researchers can use what they know (or find out what they need to know) about birds' visual sensory characteristics to make turbines more visually conspicuous to birds. The question is how to do this in a scientifically sound manner instead of via a trial-and-error approach to testing different stimuli. To accomplish this, the following four steps have proven successful in other contexts (e.g., bird-aircraft collisions):

1. Characterize the visual system of the species of interest. Birds have lateral vision, high visual acuity, high temporal visual resolution, high color space (four types of visual pigments), and better color discrimination. Eagles are not sensitive to ultraviolet light, and they, like other raptors, have a narrow binocular field. But more information is sorely needed to develop visual deterrents tuned to eagles' eyes.

2. Model the visual perception based on these characteristics. An example of this would be using a photon catch and receptor noise model to help understand how an animal 
discriminates (detects) an object from the background by using high chromatic or achromatic contrast.

\section{Develop novel stimuli that enhance the visual contrast of the wind turbines from eagles' perspectives. Parameters would include light, color, viewing angle, and pulsing rate.}

4. Measure eagles' responses to stimuli. Establish whether lights with high visual contrast lead to avoidance responses.

Researchers have to be careful when extrapolating what they know about other birds to golden eagles because the visual system configuration varies substantially among species. The key properties of golden eagle visual perception can be measured at wildlife rehabilitation centers. Researchers need to study eagles' visual systems specifically to establish the sweet spot that allows for the development of a light-based alert system that is conspicuous to golden eagles.

\section{Auditory Considerations}

By Jeff Lucas, Purdue University

Researchers can similarly characterize and measure the relevant properties of birds' (and specifically eagles') auditory systems to determine what auditory stimuli are most likely to deter eagles from entering a turbine risk zone or alert them to avoid colliding with turbines.

Relevant properties of the auditory system include auditory evoked potential, an electrical potential generated by sound waves that can be measured in birds. Auditory sensitivity, a spike in the auditory brainstem response at different sound levels, can also be measured using an audiogram to measure the minimum frequency of sound to which a species of bird is most sensitive. Eagle vocal systems provide some idea of their auditory sensitivity. Bald eagles vocalize in the $2-5 \mathrm{kHz}$ range, with strong amplitude modulation; and golden eagles use lower frequency sounds, with very strong amplitude modulation.

Developing an effective auditory deterrent would require knowing more than the minimum sound level eagles can hear. Researchers need to understand how eagles respond to louder sounds, different tones, amplitude modulations, and rapid frequency sweeps. One way to learn more about how eagles process different kinds of sounds would be to look at what neurons fire in response to different tones, modulation rates, and so on. With more information, a library of sounds, such as annoying and stress-inducing sounds, could be built, which would allow researchers to test by seeing how rapidly those sounds increase eagles' heart rates. They could also test these auditory stimuli at different intervals to see how quickly birds adapt to an audio disturbance.

Note that there is a lot of individual variation within species - not every bird finds the same stimulus equally annoying, for example — so these types of approaches may be tricky to generalize. With loud sounds, researchers would need to take care that the sound is not so loud that it damages hair cells in the birds' auditory systems. 


\section{Appendix E: Technology Overview \\ State of Eagle Detection and Deterrence Technology}

By Taber Allison, American Wind Wildlife Institute

The American Wind Wildlife Institute (AWWI) works closely with all sectors to develop science-based solutions that are consistent with the relevant policies for renewable energy development and wildlife protection. In April 2014, AWWI held a technology workshop that focused on bats and raptors. Three primary outcomes from the workshop and next steps were:

- There is no equipment impediment to feathering turbines below cut-in speed, a valuable finding that can be implemented quickly.

- Information on available technology needs to be shared.

- There is a need for independent evaluations.

AWWI created a technology catalog, populated by responses to requests for information, which is available on the website for partners and friends, and we are looking for ways to make this more broadly available. Technology categories include:

- Detection. Examples include biomonitors (people, not a technology), radar, and camera systems - typically coupled with some sort of response.

- Deterrents. Examples include light-based, acoustic, and alerts versus dissuasions (important implications for the kinds of systems and how they are tested and deployed).

- Combined systems. Examples include combining radar with cameras or other combinations of systems that best meet the need to detect and deter birds from colliding with wind turbines.

- Informed curtailment. Includes the use of biomonitors and or radars to notify the operator to turn turbines off. The sooner the target can be detected and identified, the more time operators will have to respond. Detection systems can be developed separately from deterrent technologies.

The goal of AWWI's technology verification program is to establish independent testing of technologies with replicated field studies. Key challenges include:

- We must define what we mean by "Does technology $\mathbf{X}$ work?" Being able to predict take (using the U.S. Fish and Wildlife Service's Bayesian model) is crucial so that the reduction in predicted take for a given measure can be quantified. In turn, this information reveals how much take is unavoidable and thus must be compensated per the take permit.

- Eagle collisions with turbines are statistically rare events. For this, baseline monitoring would be useful, as would enhanced fatality monitoring (less frequent but covering a wider area). Standardized collection of data so that it can be pooled and scaled up across multiple projects will help achieve a better understanding of statistically rare events. If fatality monitoring is not feasible, what can be considered a reasonable surrogate for measuring fatality reduction? 
- Credibility is essential. Research must be conducted transparently, and results must be made available to the public. How much evidence is needed to reduce uncertainty to an acceptable level?

- Sufficient funding is needed to design and conduct tests and to replicate them within and among sites. A wind project is a wind power plant, not an experimental facility. There are proprietary concerns as well as the regulatory landscape to consider. 


\section{Appendix F: Detection and Deterrent Technology Developer Panel Presentations}

By Stacy Ryan, SRC, Inc.

SRC specializes in radar systems. Typical radar systems are designed to see things that are moving; however, given that wind energy turbines themselves are moving, it is hard to detect eagles moving within a wind power plant (coming and going, yes; but within, not as much). Radar can be used to fill in some gaps where people cannot see, because of topography, and SRC has developed innovative techniques to detect eagle movement against the background movement of turbine blades. Radar is an all-weather tool, and it can operate 24 hours a day, 7 days a week. It is good for detection, but it needs to be integrated with an identification system. Systems developed to detect unmanned air systems show promise because drones exhibit a flight "behavior" similar to that to birds (i.e., low to the ground, very erratic). Gryphon, a wholly owned subsidiary of SRC, is developing a detection system for birds (http://www.gryphonsensors.com/). The company was created to build new, commercial radar focused on detecting and tracking unmanned air systems, and it has been taking the lessons learned from its extensive experience in these types of systems and bird radar to design a system optimized for this purpose. Although the radar is being heavily marketed toward detecting unmanned air systems, it will also work very well to detect birds.

Published results? SRC technologies have been tested primarily with military systems, so nothing is published at this time.

By Marcos de la Puente Nilsson, DTBird

DTBird began in 2006 to develop a modular system that uses video cameras to detect bird flights in real time and takes automatic actions to reduce collision risk. The system detects birds all around wind turbines up to a maximum of $600 \mathrm{~m}$, with a mean of two false positives per day. The first commercial installation was in 2009-2010. The system has been implemented mainly in Europe, and it is relatively new in the United States. Bird detection rates have been reported of $86 \%-96 \%$ within a radius of $150 \mathrm{~m}$ to a wind turbine and $76 \%-92 \%$ within a radius of $300 \mathrm{~m}$ to a wind turbine. The DTBird Collision Avoidance Module emits warning/discouraging sounds from the wind turbine generator to birds in collision risk. Automatic species identification in real time is not available, but the system is configured to take actions (via emitting sounds or shutting down the wind turbine) on target species/groups flying in collision risk areas. With sounds activated, reductions in bird flights have been reported at $<100 \mathrm{~m}$ from a wind turbine. Flights recorded and actions taken in real time are automatically uploaded to an online data analysis platform, where the client can review flights and request automatic service reports, which allow for the determination of collision events. To test/demonstrate DTBird system performance, the company demands a good experimental design.

Published results? References from the Norwegian Institute for Nature on successes at the Smøla wind farm (May et al. 2012) and another from the Swiss Ornithological Society (Aschwanden, Wanner, and Liechti 2015) are provided in the bibliography. 
By Karen Voltura, DeTect, Inc.

DeTect, Inc., has designed radar systems for avian detection for the U.S. Air Force and National Aeronautics and Space Administration, and it has conducted preconstruction surveys for wind facilities as well as looked at risk modeling and mitigation. Radar can be used to assess target speed, direction, and altitude relative to turbines. It can see targets farther away, but different types of instruments are needed to get a good resolution up close; therefore, visual monitoring is still used to identify targets for purposes of a response. Solutions will require integrating cameras with radar systems, thereby combining detection with deterrent technologies. For a specific turbine, it is necessary to look at risk assessment in real time. Currently, the company is testing a system located at a tar sands area to see how effective various deterrents are in changing bird behavior. Predators do not react to deterrents (with avoidance behavior) in the same way prey species do. It is possible to get a bird to move away, but not necessarily to get them to respond in a specific way.

Published results? The data belongs to DeTect's clients. Several European clients (in the United Kingdom and Belgium) have published information on measuring movement, but these results are not eagle specific.

\section{By Greg Forcey, Normandeau Associates}

Normandeau Associates has developed several remote monitoring systems; they built a detection system for bats; developed a remote condor monitoring system that interfaces with the supervisory control and data acquisition (SCADA) system at a wind facility; and tested an acoustic and thermographic offshore monitoring system (ATOM) at two sites, one terrestrial and one offshore. The results are published in a peer review journal. The terrestrial deployment for ATOM was at the University of Delaware; and the offshore deployment, which lasted for more than 12 months, was on the Frying Pan Shoals light tower off the coast of North Carolina. Two thermographic cameras operating in stereo detect flight height, direction, and velocity. These are automatically calculated using software. Thermographic detection software filters blade movement and discounts turbine blades as targets. Acoustic files are analyzed using a scanner that filters out noise. Files are identified to species using Sonabat software. Nocturnal flight calls of birds are identified to taxa by Cornell Lab of Ornithology. The company has since added visible light cameras to the system, but they have not yet been fully tested. The solar-powered system has 60 terabytes of storage, and it can use cellular and satellite modems to transfer that data remotely. It is difficult to transfer so much data, so that is a constraint. However, the detection software scans data in real time, so information on a number of targets, flight height, and speed and direction of travel is immediately available. Size calculation software has not yet been automated, but it is a small developmental step.

An acoustic mechanism will not be that useful for eagles, but thermographic and visual light cameras have potential. There is a possibility of training thermographic camera images using data from visual light cameras. Detection systems would be integrated to the turbines' SCADA systems, triggering a deterrent or shutdown. One area of improvement is the limited field of view with these cameras; therefore, using a tracking device may be a solution.

Published results? Willmott et al. 2015; the full reference is provided in the bibliography. 


\section{By Tom Hiester, RES Americas}

RES Americas partnered with Boulder Imaging to develop a camera-based system combining an array of fixed cameras to detect movement 360 degrees around a wind turbine. The system detects movement, determines whether it is a target of interest, and, if so, focuses on it with a stereoscopic high-resolution camera, providing a real-time detection and identification capability. The company wants to detect birds at a distance of $1,000 \mathrm{~m}$, and it hopes to identify whether the target is an eagle by $600 \mathrm{~m}$. One camera system can be used to cover several turbines at once. With the ability to ensure greater precision when locating eagles, the economic cost of curtailment can be minimized (lost production from curtailing a single turbine for an hour is low-on the order of $\$ 10)$.

The company is currently testing at Duke Energy's Top of the World wind power plant, but it wants to get the system tested by a third party as well. Testing is expensive, and the company needs to prove that the system works in multiple environments. They also need to know what will be deemed a valid result and obtain consensus on test protocol so that the validating solutions can be accelerated. 